Document downloaded from:

http://hdl.handle.net/10251/67991

This paper must be cited as:

Leiva García, R.; Fernandes, JS.; Muñoz-Portero, M.; Garcia-Anton, J. (2015). Study of the sensitisation process of a duplex stainless steel (UNS 1.4462) by means of confocal microscopy and localised electrochemical techniques. Corrosion Science. 94:327-341. doi:10.1016/j.corsci.2015.02.016.

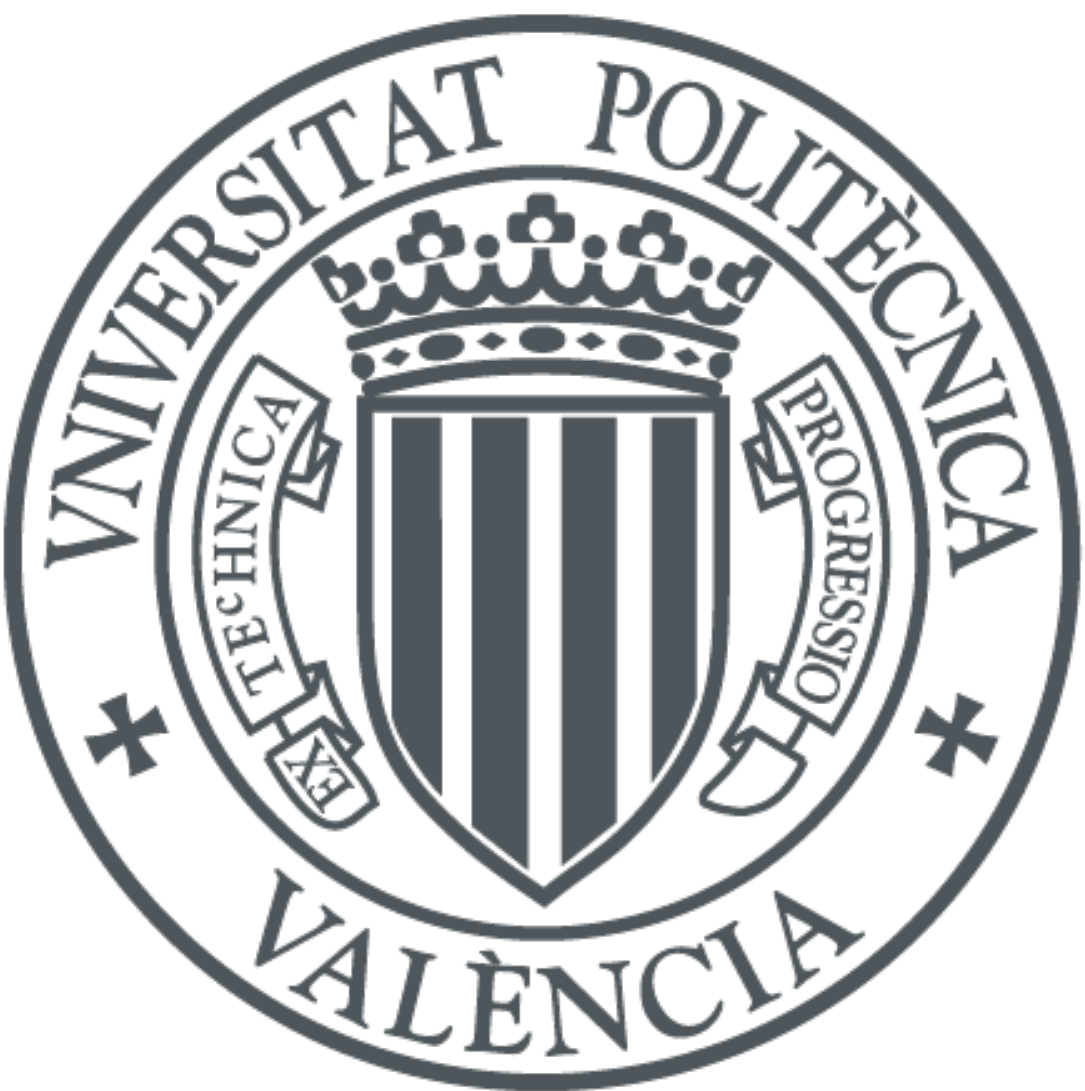

The final publication is available at

http://dx.doi.org/10.1016/j.corsci.2015.02.016

Copyright Elsevier

Additional Information 


\title{
STUDY OF THE SENSITISATION PROCESS OF A DUPLEX STAINLESS STEEL (UNS 1.4462) BY MEANS OF CONFOCAL MICROSCOPY AND LOCALISED ELECTROCHEMICAL TECHNIQUES
}

\author{
R. Leiva-García ${ }^{\mathrm{a}, \mathrm{c}}$, J.C.S. Fernandes ${ }^{\mathrm{b}}$, M.J. Muñoz-Portero ${ }^{\mathrm{a}}$, J. García-Antón ${ }^{\mathrm{a}, *}$, \\ ${ }^{a}$ Ingeniería Electroquímica y Corrosión (IEC), Departamento de Ingeniería Química y \\ Nuclear, E.T.S.I. Industriales, Universidad Politécnica de Valencia E-46071 Valencia, \\ Spain,*jgarciaa@iqn.upv.es \\ ${ }^{\mathrm{b}}$ ICEMS/DEQ/Instituto Superior Técnico/TULisbon, Av. Rovisco Pais, 1049-001 \\ Lisboa, Portugal \\ ${ }^{\mathrm{c}}$ School of Materials, University of Manchester, Manchester M13 9PL, UK
}

\begin{abstract}
When duplex stainless steels are heated, they can become sensitised and intermetallic phases can appear. In this work, samples of duplex stainless steel, UNS 1.4462, have been heated $\left(850^{\circ} \mathrm{C}\right.$ for 1 and 2 hours) in a heating unit that can be accommodated to a confocal microscope in order to study the morphological changes in-situ. The electrochemical behaviour of the samples has been analysed by means of conventional and localised electrochemical techniques. According to the results, there is a general decrease in the steel resistance to localised corrosion; this decrease can be related to defects in the formed passive film.
\end{abstract}

Keywords: A stainless steel; $C$ sensitisation; C pitting; B SECM; B EIS.

\section{Introduction}

Duplex stainless steels, such as Alloy 900 (UNS 1.4462), are considered a very attractive structural material in the field of energy/environmental systems due to their good mechanical and corrosion resistance properties. Austenite adds toughness and ferrite, which is harder, improves the mechanical and welding characteristics of the alloy. Compared to austenitic stainless steels, duplex stainless steels exhibit higher mechanical strength, comparable corrosion resistance and lower cost due to their lower Ni content. In the case of Alloy 900, it is a steel widely used in pressure vessels and piping in the chemical process industry, like digesters in the pulp and paper manufacturing and also in seawater desalination plants in marine environments. 
The trend for duplex stainless steels is to increase the $\mathrm{Cr}$ and $\mathrm{Mo}$ content in order to improve their generalised and localised corrosion resistance. However, the higher $\mathrm{Cr}$ and Mo content in duplex stainless steels can promote the precipitation of secondary phases, such as sigma phase [1-6]. These phases, which are rich in alloying elements ( $\mathrm{Cr}$ and Mo), appear when the steel is heated in a specific range of temperatures.

When duplex stainless steels are exposed to a set of temperatures lower than the solution annealing temperature, they undergo morphological changes. The metastable thermodynamic equilibrium is broken and the system seeks a more stable thermodynamic state through precipitation of intermetallic phases $(\sigma, \chi, R)$, carbides precipitates $\left(\mathrm{M}_{23} \mathrm{C}_{6}, \mathrm{M}_{7} \mathrm{C}_{3}\right)$ and a microstructural unbalance between ferrite and austenite $[1-5,7-9]$. According to the literature, it is the ferrite phase which supplies the main forming elements of the sigma phase, that is, chromium and molybdenum due to faster diffusion processes in this phase $[1,2,5]$. The formation of the new intermetallic phases provides the thermodynamic condition to the nucleation of depleted areas in chromium and molybdenum. Some of these depleted phases are secondary ferrite formed during the first minutes of the heating at $850{ }^{\circ} \mathrm{C}$ or secondary austenite, after 30 minutes at $850{ }^{\circ} \mathrm{C}$. The depletion in alloying elements leads to the formation of more defective passive films. Therefore, these areas are depleted in chromium and molybdenum and they have relevant influence on the localised attack susceptibility [1-5, 7-9]. Furthermore, not only the corrosion resistance is affected by the formation of the intermetallic phases, but also the mechanical properties of the material. The sigma phase is the mainly embrittlement factor when duplex stainless steels are exposed at the temperature range from $600{ }^{\circ} \mathrm{C}$ to $1000{ }^{\circ} \mathrm{C}$. Factors such as yield stress or the Charpy 
impact toughness may decrease as a consequence of the increase in the sigma phase volume [10-12].

Therefore, the study of solid-state phase transformations in steels is important to avoid inadequate heat treatments that may result in sensitised materials. It is possible to use in-situ observational techniques [13-15] to study the behaviour of migrating interfaces, one of these techniques being the hot stage confocal scanning laser microscopy (CSLM), which was utilised in the current research [16-18]. On the other hand, due to the relation between the formation of new phases and the drop in corrosion resistance, it is also important to determine the influence of the sensitisation processes on the electrochemical behaviour of duplex steels.

Thus, the aim of this work is the study of the sensitisation process at $850{ }^{\circ} \mathrm{C}$ during 1 and 2 hours and its effect on the electrochemical behaviour of Alloy 900 using high temperature confocal microscopy and different electrochemical techniques (conventional and localised), such as scanning electrochemical microscopy, electrochemical impedance spectroscopy or localised electrochemical impedance spectroscopy.

\section{Experimental procedure}

\subsection{Materials}

The material used in this work was a duplex stainless steel, Alloy 900 (UNS 1.4462), whose composition in weight is: $22.34 \% \mathrm{Cr}, 4.85 \% \mathrm{Ni}, 1.59 \% \mathrm{Mn}, 0.35 \% \mathrm{Si}, 2.69 \%$ Mo, $0.13 \% \mathrm{Cu}, 67.80 \% \mathrm{Fe}, 0.02 \% \mathrm{P}, 0.03 \% \mathrm{C}, 0.20 \% \mathrm{~N}$, and $0.01 \% \mathrm{Ti}$. The 
electrodes of Alloy 900 were machined and cylindrically shaped $(5 \mathrm{~mm}$ in diameter and $5 \mathrm{~mm}$ in height).

\subsection{In-situ Heat Treatments}

Before the heat treatments, the samples were wet abraded with silicon carbide paper up to $\# 4000$, and then polished with alumina of $1 \mu \mathrm{m}$, before being finally rinsed with water and ethanol and dried with hot air. Then, the samples were put in the crucible on the "Limkan" heating unit that was closed in order to maintain an inert atmosphere. Prior to heating, an argon flow was passed through the heating unit during 30 minutes in order to purge the oxygen; during the tests this argon atmosphere was maintained. After that, a heating ramp was programmed from $25{ }^{\circ} \mathrm{C}$ to $850{ }^{\circ} \mathrm{C}$ and this temperature was held for 1 or 2 hours, with images of the surface evolution being simultaneously obtained. These images were acquired using an "Olympus LEXT 3100" laser confocal microscope where the heating unit can be accommodated. This microscope gives fast, accurate, non contact measurements of surface topography in three dimensions.

Finally, the materials were examined after the heat treatments by scanning electron microscopy (SEM) and energy dispersive X-ray analysis (EDS) to estimate the morphological transformations resulting from the heating process.

After the heat treatments and the microscopic characterisation, the samples were lengthway halved and an electrical connection was made to them in order to allow for electrochemical measurements. Pairs of individual unsensitised and sensitised samples were then mounted together in epoxy resin as shown in Figure 1, this system being used in all the electrochemical tests. Before all the electrochemical tests, the samples 
were wet abraded with silicon carbide paper up to $\# 4000$, before being finally rinsed with water and ethanol and dried with hot air.

\subsection{Polarisation curves}

Polarisation curves were obtained using a PGSTAT302N potentiostat from AUTOLAB. Tests were carried out in a three-electrodes cell, using the resin-mounted alloy as working electrode, a $\mathrm{Ag} / \mathrm{AgCl}(3 \mathrm{M} \mathrm{KCl})$ reference electrode and a platinum auxiliary electrode. Potentiodynamic polarisation curves were obtained for the unsensitised Alloy 900 and for both samples of sensitised Alloy 900 in a naturally aerated $1 \mathrm{mM} \mathrm{NaCl}$ aqueous solution, from $-1000 \mathrm{mV}$ vs $\mathrm{Ag} / \mathrm{AgCl}$ to $1000 \mathrm{mV}$ vs $\mathrm{Ag} / \mathrm{AgCl}$ at $0.5 \mathrm{mV} \cdot \mathrm{s}^{-1}$ sweep rate.

\subsection{Electrochemical Impedance Spectroscopy (EIS) Measurements}

The EIS measurements were made at open circuit potential (OCP) after 1 hour of immersion in the naturally aerated $1 \mathrm{mM} \mathrm{NaCl}$ solution and at different potentials in the passive range from $0.2 \mathrm{~V}$ vs $\mathrm{Ag} / \mathrm{AgCl}$ to $1 \mathrm{~V}$ vs $\mathrm{Ag} / \mathrm{AgCl}$ in order to study the effect of the sensitisation on the metal/electrolyte interface. The voltage perturbation amplitude was $10 \mathrm{mV}$, in the frequency range of $100 \mathrm{kHz}$ to $1 \mathrm{mHz}$. The temperature of the solution was $25{ }^{\circ} \mathrm{C}$. Additionally, Mott-Schottky plots were obtained in the samples passivated at OCP by sweeping the potential from the OCP value in the negative direction with potential steps of $75 \mathrm{mV}$ with an amplitude signal of $10 \mathrm{mV}$. A high scanning rate was used to avoid electroreduction of the film and changes in film thickness during the measurements. At a sufficiently high scanning rate, the defect structure within the film is "frozen-in", which avoids the defect density from being affected by potential [19-21]. A value of $5 \mathrm{kHz}$ has been used in this work to eliminate 
capacitance dependence on frequency since tests performed on the system used demonstrated that the capacitance becomes almost independent of frequency at approximately $5 \mathrm{kHz}$.

\subsection{Scanning Electrochemical Microscopy (SECM)}

SECM tests were performed using a "Sensolytics" workstation. The SECM was operated in "feedback mode". A platinum microelectrode tip $25 \mu \mathrm{m}$ in diameter, a platinum rod as counter-electrode, and a silver-silver chloride with $3 \mathrm{M} \mathrm{KCl}$ reference electrode were used. Samples were immersed in a $1 \mathrm{mM} \mathrm{NaCl}$ solution at $25^{\circ} \mathrm{C}$. All the tests were carried out in naturally aerated solutions. Oxygen was used as the electrochemical mediator at the tip, the reduction of oxygen on the microelectrode being used to establish the height of the tip over the sample and also to record the reactivity of the surface during the test. A cyclic voltammogram was recorded at a scan rate of 0.05

$\mathrm{V} \cdot \mathrm{s}^{-1}$ from $0 \mathrm{~V}$ vs $\mathrm{Ag} / \mathrm{AgCl}$ to $-1 \mathrm{~V}$ vs $\mathrm{Ag} / \mathrm{AgCl}$ and the obtained data were then used in order to choose the polarisation potential of the tip. The establishment of the operating distance of the tip to the sample surface was performed in relation to both materials of the sample, notably (a) the unsensitised alloy and (b) the sensitised alloy. SECM line scans were obtained at open circuit potential after 1 hour of immersion by rastering the surface at steps of $25 \mu \mathrm{m}$ in the $\mathrm{X}$ direction and the scan length $9000 \mu \mathrm{m}$.

\subsection{Localised Electrochemical Impedance Spectroscopy}

The LEIS measurements were performed through a PAR Model 370 Scanning Electrochemical Workstation coupled to a Solartron 1286 potentiostat and a Solartron 1250 frequency response analyser. The LEIS unit makes use of a five-electrode configuration, consisting of a conventional three-electrode arrangement (i.e. a reference electrode, a counter electrode and the substrate as the working electrode) to achieve 
potentiostatic control, and the LEIS probe ( $\mathrm{Pt}$ bi-electrode) to measure the local potential gradient in the solution above the surface, which is then related to the currents flowing in the system. All the LEIS measurements were obtained in a diluted $(1 \mathrm{mM}$ $\mathrm{NaCl}$ ) solution to ensure a good resolution in the current measurement. The measuring frequency was $2 \mathrm{~Hz}$ and an $\mathrm{AC}$ disturbance signal of $10 \mathrm{mV}$ was applied at open circuit potential (OCP), after 1 hour of immersion in the $1 \mathrm{mM} \mathrm{NaCl}$ solution, and at different potentials in the passive range from $0.2 \mathrm{Vvs} \mathrm{Ag} / \mathrm{AgCl}$ to $1 \mathrm{~V}$ vs $\mathrm{Ag} / \mathrm{AgCl}$. The microprobe was stepped over a line of $9000 \mu \mathrm{m}$ to obtain the admittance profiles and over a designated area of the electrode surface $(9000 \mu \mathrm{m} \times 1500 \mu \mathrm{m})$ to obtain the admittance maps. The distance between the probe and the samples was $1 \mathrm{~mm}$ and the used lateral resolution 150 microns.

\section{Results and discussion}

All the tests were repeated at least three times and the results presented in this section represent the mean value and the error bands represent the standard deviation of each parameter regarding this mean value. The curves presented in this work are a representative example of those obtained during the experiments.

\subsection{In-situ Heat Treatments}

CSLM images of the surface evolution of the samples during the heating process at 850 ${ }^{\circ} \mathrm{C}$ during 2 hours are shown in Figure 2. Initially, at $25{ }^{\circ} \mathrm{C}$, the surface is homogeneous, without visible differences between the phases. When the temperature reaches $500{ }^{\circ} \mathrm{C}$ (Figure 2 a)), both phases are clearly differentiated; austenite (the lightest phase) has a higher thermal coefficient than ferrite (the darkest phase), thus

austenite grains grow faster than ferrite grains. According to the literature, when a duplex stainless steel is heated, new phases (sigma and chi) appear and the percentage 
of one of the initial phases (ferrite) decreases [1-5]. Therefore, when temperature is above $750{ }^{\circ} \mathrm{C}$ migration fronts begin to appear in the interface between ferrite and austenite grains, and, the nucleation of the new phases begins in the boundaries between austenite and ferrite (Figures 2 b) and c)), the ferrite phase being the precursor phase $[3,22]$. The height of these fronts increases with respect to the neighbouring areas; this is the reason why they are clearly visible during heating. Some authors [18] have suggested that the temperature at which the growth is first observed will be somewhat higher than the thermodynamic transformation temperature; however, this difference is normally not higher than $5{ }^{\circ} \mathrm{C}$; thus, the temperature at which the formation of new phases in Alloy 900 begins is over $750{ }^{\circ} \mathrm{C}$. On the other hand, these fronts become much wider as the temperature and the duration of the heating process increase (Figure 2 d)). Furthermore, the roughness of the ferrite grains greatly increases, showing a jagged surface, due to the segregation of the alloying elements within this phase (Figure 2 e)) Finally, during the constant temperature heating the surface smoothens and the migration fronts begin to be less noticeable, as shown in Figures 2 g) and $\mathbf{h})$.

The contrast changes observed by the CSLM system during solid phase transformations are the result of topographical modifications caused by surface deformation due to the displacive and dilatometric nature of phase transformations or the formation of intermetallic phases [23-25]. The relationship between these processes generally means that the faster the migration rate of the interface, the less likely it is to be smoothed before the migrations fronts can be observed [18]. This reveals a close relation between relief fronts and the migration of interface boundaries [24, 25]. Roughness was measured at different steps of the heat treatment (Figure 3). When temperature rises 
from $600{ }^{\circ} \mathrm{C}$ to $750{ }^{\circ} \mathrm{C}$ roughness greatly increases due to the formation of the migration fronts observed in Figure 2. Between 750 and $850{ }^{\circ} \mathrm{C}$ the roughness values go on increasing. On the other hand, during the isothermal step the roughness slightly decreases along the 2 hours of the heat treatment, probably due to the smoothing effect of the surface diffusion [23-25].

After the heat treatment, the samples were characterised using SEM (backscattered electrons mode), Figure 4 shows the SEM micrographs of the Alloy 900 samples in the unsensitised and sensitised state at $850{ }^{\circ} \mathrm{C}$ during 1 and 2 hours. The heat treatment causes the formation of two clear new phases (the brightest phases) and the drop in the ferrite percentage value, as shown in Figure 4. According to the literature, between 700 ${ }^{\circ} \mathrm{C}$ and $1000{ }^{\circ} \mathrm{C}$, the percentage of ferrite decreases due to its decomposition into secondary phases, such as the sigma phase or secondary austenite $[1,2,5,7,26]$. Therefore, the new phases can be identified as sigma and chi phases [1, 26-30]. The area percentage of these phases was obtained by image analysis and is presented in Figure 5. It is important to highlight that the percentage of ferrite decreases whereas austenite increases and the formation of new phases occurs. Therefore, the ferrite phase, which is rich in alloying elements, such as chromium and molybdenum, is the precursor for the formation of new phases, confirming the observations made during the heat treatments $[1,2,5]$. Furthermore, when the duration of the heating step increases to 2 hours the percentage of the chi phase drops whereas the percentage of the sigma phase increases. Several studies have concluded that, although the chi phase forms earlier than the sigma phase, it transforms to the second one upon prolonged heating [31-33]. 
The chemical compositions of ferrite, austenite, sigma and chi phases in the alloy heated for 1 and 2 hours at $850^{\circ} \mathrm{C}$, analysed by SEM-EDS are presented in Table 1. The chromium and molybdenum contents in the sigma and chi phases are higher compared with those in the neighbouring ferrite and austenite phases. Due to their higher $\mathrm{Cr}$ and Mo contents, it is expected that the formation of these intermetallic phases depletes the surrounding areas from alloying elements, leading to a decrease in the corrosion resistance of Alloy 900 [2, 27, 34].

\subsection{Polarisation Curves}

Figure 6 shows the polarisation curves of Alloy 900 in the unsensitised state and in both sensitised states, in $1 \mathrm{mM} \mathrm{NaCl}$ solution; this is the same solution used in the localised techniques where the sensitivity is better with diluted solutions. Some differences as a consequence of the sensitisation process, can be observed between the curves. The cathodic current density is higher in both sensitised samples than in the unsensitised sample. On the other hand, the pitting potential, established as the potential when the current density reached $100 \mu \mathrm{A} \cdot \mathrm{cm}^{-2}$ [35], is only reached in the heated samples while in the case of the unsensitised Alloy 900 no breakdown potential is observed. There is not any current density raise after the transpassive region and the current increase only takes place after the oxygen evolution potential. When the samples were examined with SEM after the polarisation curve, no pits were observed in the unsensitised sample while pits could be observed close to the new intermetallic phases (sigma and chi), as shown in Figure 7. This is an indication that the depleted areas become more susceptible to the localised attack [1-5, 7-9, 27, 34]. 
From the polarisation curves, different electrochemical parameters (corrosion potential $\left(\mathrm{E}_{\text {corr }}\right)$, pitting potential $\left(\mathrm{E}_{\mathrm{p}}\right)$, passivation current density $\left(\mathrm{i}_{\mathrm{p}}\right)$ and cathodic limiting current density (between $-0,7$ and $-0.9 \mathrm{~V}$ vs $\mathrm{Ag} / \mathrm{AgCl})\left(\mathrm{i}_{\mathrm{cl}}\right)$ ) were obtained for the different materials (Table 2).

According to the results of Table 2, the heated samples present lower pitting potential than the unsensitised sample, which is only presenting the raise in the current after reaching the oxygen evolution potential. Additionally, the sample heated at $850{ }^{\circ} \mathrm{C}$ for 2 hours presents the lowest pitting potential value, indicating the lowest resistance to localised corrosion of the tested specimens. Therefore, the formation of the sigma phase causes a decrease in the corrosion resistance of the alloy. These results are in agreement with several authors who propose that the sensitisation process increases the susceptibility of stainless steels to the formation of pits [2, 36-41]. A clear increment in the passive current density is not observed, probably consequence of the use of a diluted solution. On the other hand in the case of the cathodic limit current density an slight increase is observed.

\subsection{EIS measurements}

The superior corrosion resistance of stainless steels, such as Alloy 900, is closely related to the passive film formed on their surface. It is generally accepted that the passive film formed on the surface of stainless steels is composed of two interpenetrating layers [4249]. The compact inner layer, known as barrier layer, is mainly composed of chromium oxides which are the major contributors. The porous outer layer is mainly composed of iron oxides and hydroxides. On the other hand, the effectiveness of this passive film may decrease as a consequence of the depleted regions formed during the sensitisation 
process of steels. In the case of duplex stainless steels, the depletion in alloying elements may appear in the areas adjacent to the new intermetallic phases (concentration points of $\mathrm{Cr}$ and $\mathrm{Mo}$ ). These depleted areas (i.e. secondary austenite or secondary ferrite) may favour the formation of defects on the passive film that increase diffusion throughout the passive film [50-52]. Moreover, if the $\mathrm{Cr}$ content decreases to values below the threshold corresponding to autopassivation, these low $\mathrm{Cr}$ content zones may no longer correspond to a stainless steel and their local corrosion will be expected.

Therefore, to investigate the properties of the passive films formed on the Alloy 900 in its different states, impedance spectra were recorded at different passive potentials, including open circuit potential conditions. In this way it was possible to determine the evolution of passive films in the $1 \mathrm{mM} \mathrm{NaCl}$ solution and how the sensitisation process affected these films. Figures 8 and $\mathbf{9}$ show the Nyquist and Bode-phase diagrams for the EIS measurements carried out at the different potential conditions under study. In general, the EIS diagrams exhibit a typical passive state shape characterised by high impedance values with non-ideal capacitive behaviour, suggesting that a stable film is formed on the entire electrode surface [53-57]. It can be observed that the capacitive semicircle of the unsensitised sample was much larger than those of the heated samples. Additionally, with the increase in heating time, the size of the semicircle decreased. This behaviour is in agreement with the results obtained by other authors working with different stainless steels [50-52].

On the other hand, in the case of the sensitised samples, there is a noticeable decrease in the size of the semicircle when the sensitised samples are polarised within the 
transpassive potentials $(0.8$ and $1 \mathrm{~V}$ vs $\mathrm{Ag} / \mathrm{AgCl})$, this decrease being related to the breakdown of the passive film. Also the Bode phase shows a decrease from the ideal capacitor behaviour with the increase in the applied potential, indicating a less protective film. This decrease is less noticeable in the case of the unsensitised sample, which remains closer to the ideal capacitor behaviour than the sensitised samples at all the studied potentials.

The stability of the system is crucial for the validity of EIS measurements. An independent check of the validity of impedance data (that is, compliance of the system with the constraints of the Linear Systems Theory (LST)) is possible through the use of Kramers-Kronig (K-K) transforms. The Kramers-Kronig transforms have been applied to the experimental impedance data by transforming the real axis into the imaginary axis and the imaginary axis into the real axis and then comparing the transformed quantities with the respective experimental data. In all the cases it could be observed that the K-K transforms were almost exact, following the same tendency as the experimental values, indicating the system remained stable during the measurement time.

Figure 10 shows the equivalent circuit (EC) that has been widely used to interpret EIS spectra of passive films having a two-layer structure [42, 54, 58-60], so this circuit was used to simulate the electrochemical behaviour of Alloy $900 / \mathrm{NaCl}$ solution. In this model, $\mathrm{R}_{\mathrm{S}}$ corresponds to the resistance of the electrolyte; $\mathrm{CPE}_{1}$ is related to the double layer capacitance, $\mathrm{R}_{1}$ is the additional solution resistance inside the pores of the outer layer and $\mathrm{R}_{2}$ and $\mathrm{CPE}_{2}$ corresponds to the resistance and capacitance of the inner barrier layer, respectively. A constant-phase element (CPE) representing a shift from the ideal capacitor was used instead of the capacitance itself. The CPE of each subcircuit (inner 
and outer) was converted into a pure capacitance $(\mathrm{C})$ by means of the following equation:

$$
C=\frac{(Q \cdot R)^{1 / n}}{R}
$$

The sum of $R_{s}, R_{1}$ and $R_{2}$ was defined as the polarisation resistance, $R_{P}$, and is related to the corrosion resistance of the metal. Table 3 shows the values of every parameter for the three tested samples of Alloy 900.

The value of $\mathrm{R}_{1}$ (the additional solution resistance inside the pores of the outer layer) depends strongly on the existence of pores, channels or cracks, into which the electrolyte can penetrate and thus provides a sensitive indication of the appearance of such defects in the passive film. If the outer layer is very porous, the value of $R_{1}$ is close to the value of the solution resistance [44], as it happens in this work. Moreover, this value decreases as a consequence of the heat treatment. On the other hand, the values of $\mathrm{R}_{2}$ (inner layer resistance) are far higher than the $\mathrm{R}_{1}$ values, indicating a more compact film with less defects, which is the typical case on a barrier layer. However, it is noticeable the effect of the heat treatment, because the values of $\mathrm{R}_{2}$ are clearly lower for the samples heated at $850{ }^{\circ} \mathrm{C}$ for 1 and 2 hours than for the unsensitised steel. Additionally, this effect is greater with the time of the heat treatment. Furthermore, the capacitance values, which may be inversely related with the thickness of the film, increase in a general way as a consequence of the heat treatment, indicating a possible decrease in the thickness of the formed passive film or an increase of the interfacial surface consequence of a more defective film. 
Regarding the trend of the polarisation resistance with the applied potential, it can be observed that this parameter increases with the imposed potential until the potential reaches $0.6 \mathrm{~V}$ vs $\mathrm{Ag} / \mathrm{AgCl}$. When the samples are polarised in this range of potentials, the growth of the passive film is favoured, increasing its polarisation resistance and thickness. However, when the samples are polarised at higher potentials (within the transpassive region for the sensitised samples), the insulating properties of the passive film decrease compared to those polarised at lower potentials (less polarisation resistance and higher capacitances).

Therefore, the sensitisation process leads to a more conductive passive film that presents lower polarisation resistance. This more conductive layer could be related to defects that are a consequence of the areas depleted in alloying elements (secondary ferrite and secondary austenite) after the formation of intermetallic phases [50-52]. Moreover, the effect of the sensitisation is greater on the $\mathrm{R}_{2}$ values that present a strong decrease as a consequence of the heat treatment, because the compounds of the inner layer are mainly chromium oxides, one of the depleted alloying elements. Thus, the increase in the conductivity of the passive film after the heat treatment may explain the greater susceptibility to pitting corrosion of the sensitised samples in the potentiodynamic curves [50-52]. In order to analyse the semiconductive properties of the passive films of the unsensitised and sensitised Alloy 900 a Mott-Schottky analysis was conducted with the samples passivated at open circuit potential.

The electrochemical capacitance of the passive film/electrolyte interface was measured as a function of the applied potential to assess the semiconducting properties of the films formed on Alloy 900. Since the space charge region developed in the passive film 
and the Helmholtz layer can be considered as two capacitors in series, the measured capacitance of the film/electrolyte interface can be written as [42]:

$$
\frac{1}{C}=\frac{1}{C_{S C}}+\frac{1}{C_{H}}
$$

where $C_{S C}$ is the capacitance of the space charge layer and $C_{H}$ the capacitance of the Helmholtz layer.

It is generally accepted that the capacitance of the space charge layer is very small compared with that of the Helmholtz layer and the measured interfacial capacitance can be regarded as that of the space charge layer when the potential perturbations are applied with a sufficiently high frequency [61, 62]. However, several sttudies [63] have shown that a significant part of the potential difference at the semiconductor/electrolyte interface extends to the Helmholtz layer in the solution. Therefore, $C_{H}$ should not be neglected. In this way, the space charge capacitance of $p$ - and n-type semiconductors is given by Equations 3 and 4, respectively [42, 64, 65].

$$
\begin{array}{ll}
\frac{1}{C^{2}}=\frac{1}{C_{H}^{2}}+\frac{2}{\varepsilon \varepsilon_{0} e N_{D}}\left(E-E_{F B}-\frac{k T}{e}\right) & \text { n-type } \\
\frac{1}{C^{2}}=\frac{1}{C_{H}^{2}}-\frac{2}{\varepsilon \varepsilon_{0} e N_{A}}\left(E-E_{F B}-\frac{k T}{e}\right) & \text { p-type }
\end{array}
$$

where $\varepsilon$ is the dielectric constant of the passive film (a value of 15.6 has been assumed for the chromium and iron oxides formed on stainless steels $[65,66], \varepsilon_{0}$ is the vacuum permittivity $\left(8.85 \cdot 10^{-14} \mathrm{~F} / \mathrm{cm}\right), e$ is the electron charge $\left(1.60 \cdot 10^{-19} \mathrm{C}\right), N_{D}$ and $N_{A}$ are respectively the donor and acceptor densities, $E_{F B}$ is the flat-band potential $k$ is the Boltzmann constant $\left(1.38 \cdot 10^{-23} \mathrm{~J} / \mathrm{K}\right)$ and $T$ is the absolute temperature. 
Figure 11 shows the plot of $\mathrm{C}^{-2}$ vs potential, E, (Mott-Schottky plots) for the films formed on Alloy 900 at OCP. Mott-Schottky plots clearly reveal the existence of three regions in the films formed after the heat treatments, where a linear relationship between $C^{-2}$ and $E$ can be observed The region comprised between -1.5 and $-0.9 \mathrm{~V}$ vs $\mathrm{Ag} / \mathrm{AgCl}$ (Region I) possesses a slope close to $0^{\circ}$ and can be associated to the flat band region. On the other hand, the regions II (from -0.8 to $-0.3 \mathrm{~V}$ vs $\mathrm{Ag} / \mathrm{AgCl}$ ) and III (after $-0.3 \mathrm{~V}$ vs $\mathrm{Ag} / \mathrm{AgCl}$ ) present positive and negative slopes respectively. The positive slope of the Mott-Schottky plot at lower potentials in the passive region, indicates that the oxide layer behave like n-type semiconductors [67, 68]; this is associated with an outer oxide film mainly composed of iron oxides and hydroxides. Region III is characterised by a decrease in the Mott-Schottky plots. In this region, a modification in the electronic properties of the passive film from n-type to p-type semiconductivity is related to an increase in the conductivity of the film due to the solid state oxidation of $\mathrm{Cr}$ (III) to $\mathrm{Cr}$ (VI) and the change in semiconductivity behaviour can be explained by the generation of cation vacancies (electronic acceptors and p-type dopants) at the film/solution interface [68-70].

From the slopes of the linear zones in Figure 11, $\mathrm{N}_{\mathrm{D}}$ and $\mathrm{N}_{\mathrm{A}}$ can be calculated for $\mathrm{n}$ type and p-type semiconductors using Equations 3 and 4 respectively. Table 4 shows the values of $\mathrm{N}_{\mathrm{D}}$ and $\mathrm{N}_{\mathrm{A}}$ for Alloy 900 with the different heat treatments. It can be observed in Table 4 that $N_{D}$ is greater for the sensitised samples than for the unsensitised sample, this difference being more noticeable in the case of the Alloy 900 heated at $850{ }^{\circ} \mathrm{C}$ during 2 hours. According to the point defect model [71, 72], aggressive anions can absorb in surface oxygen vacancies, which leads to the generation of a cation vacancy/oxygen vacancy via a Schottky pair type of reaction. The oxygen 
vacancies in turn react with additional anions at the film/electrolyte interface to generate more cation vacancies, this autocatalytic process eventually may lead to the breakdown of the passive film. Thus, the $\mathrm{N}_{\mathrm{D}}$ value characterises the affinity of aggressive anions for the passive film. It is observed that with the increase in the percentage of intermetallic phases (they lead to the formation of areas depleted in alloying elements) $\mathrm{N}_{\mathrm{D}}$ increases. Therefore, the sensitised samples present a larger sensitivity to pit nucleation related with an easier incorporation of aggressive anions to the passive film. This result is coincident with the lower breakdown potential observed in the potentiodynamic curves for the sensitised specimens and also explains the lower polarization resistance observed in the EIS data.

\subsection{SECM measurements}

SECM measurements were carried out in order to study the different electrochemical activity of the surface of the samples as a consequence of the heat treatment. One of the most important cathodic reactions occurring during corrosion in aerated solutions is the reduction of dissolved oxygen and this reaction can be used in the platinum microelectrode tip to monitor the electrochemical activity of the studied samples [7375]:

$$
\mathrm{O}_{2}+2 \mathrm{H}_{2} \mathrm{O}+4 \mathrm{e}^{-} \rightarrow 4 \mathrm{OH}^{-}
$$

The progress of this reaction can be followed by setting the tip at $-0.7 \mathrm{~V}$ vs $\mathrm{Ag} / \mathrm{AgCl}$. Under these conditions the amperometric detection in the tip of oxygen is under the limiting current of reduction of oxygen, as confirmed by the cyclic voltammogram shown in Figure 12. Therefore, with the tip polarised at $-0.7 \mathrm{~V}$ vs $\mathrm{Ag} / \mathrm{AgCl}$ it is 
possible to monitor, in solution, the consumption of oxygen with time at the surface of the alloy in both its sensitised and unsensitised conditions (this consumption being a consequence of the electrochemical processes which are taking place on the metal surface).

Once the polarisation potential of the tip was selected, approach curves were carried out in order to choose the operating distance at which the tip would raster above the sample. The zero position of the tip, that is, where the approach curves begin, was an arbitrary position such that the influence of the sample on the probe's response was not significant. From this zero position the tip was moved down towards the sample; therefore, the approach curves record how the proximity of the tip to the sample affects the diffusion of oxygen to the tip and hence the magnitude of the current. Figure $\mathbf{1 3}$ shows the approach curves obtained over the different tested materials. According to the results presented in a previous work, there is a competitive reaction in the consumption of oxygen, notably between the tip and the metal surface [75]. Thus, lower reduction currents at the probe tip indicate higher consumption of oxygen at the sample. Then, based on the approach curves, the oxygen reduction is higher over the surface of Alloy 900 in its sensitised state than in its unsensitised state. Furthermore, the differences are greater when samples are heated for 2 hours. Therefore, the selected operating distance of the microelectrode above the sample was the distance where the differences in current between the registered approach curves were greatest (see Figure 13).

Once the operating distance of the tip was selected, line scans of the sample were conducted, as shown in Figure 14. In order to normalise the data, values of the current registered in the tip over the sensitised and unsensitised sample were divided by the current registered over the resin, eg, $\mathrm{I}_{\text {tip (metal) }} / \mathrm{I}_{\text {tip (resin). }}$. 
The magnitude of oxygen reduction occurring at the tip, when it was above the steel surface, is comparatively low compared to that above the epoxy resin. Furthermore, the amount of oxygen reduction on the tip decreases when it passes from the unsensitised sample to the sensitised sample. Therefore, the consumption of oxygen is greater over the sensitised samples, the increased consumption being associated with a higher cathodic activity and, according to the mixed potential theory, to higher anodic (i.e. corrosion) activity. The higher cathodic activity also indicates a greater electronic conductivity of the passive film formed on the sensitised sample. Several authors [7679], proposed that the reduction pathway is influenced by the surface composition of the electrode and oxides have an important role to play in the oxygen reduction kinetics [80]. Therefore, any chromium depleted areas formed in the sensitised alloy can lead to the formation of a more conductive passive film that promotes higher oxygen reduction on the electrode surface. This observation confirms the results obtained from the polarisation curves (Figure 6), where the cathodic current density was higher in the sensitised samples than in the unsensitised sample. Furthermore, this more conductive passive film leads to a decrease in the localised corrosion resistance (lower pitting potential in the sensitised samples). Additionally, these results are in agreement with the polarisation resistance obtained from the EIS data. The polarisation resistance was lower and the donor density was greater in the sensitised specimens than in the unsensitised one. This relation between the donor density and the cathodic current density was previously reported in the literature [81].

\subsection{LEIS measurements}

Localised impedances have been used previously to measure localised processes in metals, studying pit growth, surface dissolution or coatings degradation [82-85]. 
Therefore, LEIS measurements may be used in order to evaluate the galvanic coupling between the unsensitised Alloy 900 and Alloy 900 with different degrees of sensitisation. In the previous sections, the effect of the sensitisation was studied with the different samples uncoupled. Conversely, in this point, LEIS measurements at different potentials were carried out with coupled pairs (unsensitised Alloy 900/sensitised Alloy 900). Profiles of admittance of the tested samples were obtained at a frequency of $2 \mathrm{~Hz}$. Figures 15 and 16 present these profiles of the pairs unsensitised Alloy 900/Alloy 900 heated at $850{ }^{\circ} \mathrm{C}$ for 1 hour and unsensitised Alloy 900/Alloy 900 heated at $850{ }^{\circ} \mathrm{C}$ for 2 hours, respectively.

In the case of the pair with the sample heated at $850^{\circ} \mathrm{C}$ for 1 hour, it can be observed that the admittance is greater over the sensitised sample in all the cases; therefore, the passive film is more conductive in the sensitised sample On the other hand, when potentials of $0.4 \mathrm{~V}$ vs $\mathrm{Ag} / \mathrm{AgCl}$ or $0.6 \mathrm{~V}$ vs $\mathrm{Ag} / \mathrm{AgCl}$ are imposed to the pair, there is a decrease in the admittance values in both members of the pair. However, when $0.8 \mathrm{~V}$ vs $\mathrm{Ag} / \mathrm{AgCl}$ are applied, the admittance of Alloy 900 in the as-received and sensitised state increases due to the partial dissolution of the passive film. This behaviour is coincident with the evolution of the polarisation resistance observed in the EIS measurements. Finally, when the pair is polarised at $1 \mathrm{~V}$ vs $\mathrm{Ag} / \mathrm{AgCl}$, the admittance drops in the asreceived Alloy 900 and strongly increases in the heated sample, this increase being motivated by the breakdown of the passive film and the formation of pits. On the other hand, the decrease in the admittance values over the as-received sample may be due to the high activity over the sensitised member of the pair that leads to a less active unsensitised area. In order to reinforce this observation, Figure 15 d) shows the great increase in the admittance over the entire surface of the sensitised sample. 
A similar behaviour can be observed in the pair with the sample sensitised at $850{ }^{\circ} \mathrm{C}$ for 2 hours. Admittance is greater on the sensitised member of the pair at all the tested potentials, indicating a higher conductive passive film than the unsensitised Alloy 900. With the increase of the polarisation potential there is a general decrease in both members of the pair as a consequence of the formation of a thicker passive film until the potential of $0.8 \mathrm{~V}$ vs $\mathrm{Ag} / \mathrm{AgCl}$ is applied. At this potential, the admittance decreases in the as-received Alloy 900 and increases in the sensitised member of the pair. Figure 16 d) shows a map of the admittance over the surface of the pair polarised at $1 \mathrm{~V}$ vs $\mathrm{Ag} / \mathrm{AgCl}$ where the great increase in the admittance on the surface of the sensitised sample is noticeable due to the breakdown of the passive film. Furthermore, the admittance of the as-received sample decreases when the coupled pair is polarised at potentials of 0.8 and $1 \mathrm{~V}$ vs $\mathrm{Ag} / \mathrm{AgCl}$. Thus, the anodic activity in the sensitised member of the pair clearly turns the unsensitised sample in the cathodic member of the electrically coupled pair, leading to its protection against corrosion (less conductive passive film).

The maximum admittance values were calculated for every sample at the different experimental conditions ( Figure 17). As it was observed in the admittance profile, the maximum admittance values are lower in the case of the unsensitised member of the pair. The unsensitised Alloy 900 coupled with the sample heated during two hours presents lower admittance values than when it is coupled with the sample heated for one hour. The samples heated at $850{ }^{\circ} \mathrm{C}$ during 1 and 2 hours present similar admittance values at all potentials, except when the pair is polarised at 0.8 and $1 \mathrm{~V}$ vs $\mathrm{Ag} / \mathrm{AgCl}$, where the sample heated for 2 hours presents admittance values slightly higher than the 
sample heated during 1 hours, indicating a more active surface. This fact is in agreement with the lower polarisation resistance observed in the EIS measurements and with the higher $\mathrm{N}_{\mathrm{D}}$ obtained in the Mott-Schottky analysis.

Regarding the dependence of the admittances on the applied potential, it can be observed that the admittance values decrease in all the samples with the increase in the applied potential, until the potential of $0.6 \mathrm{~V}$ vs $\mathrm{Ag} / \mathrm{AgCl}$ is reached; after that, the values begin to increase with the imposed potential. Only in the case of the as-received sample coupled to the sample heated at $850^{\circ} \mathrm{C}$ during 2 hours, the admittance decreases with the potential in all the polarisation range as a consequence of the electrical coupling effect.

In a previous work carried out with LEIS measurements by other authors [86], a decrease in the impedance modulus was observed over the sensitised area of a welded AISI 304 stainless steel, being indicative of an area with higher electrochemical activity. Thus, the differences in the oxide film formation over the sensitised stainless steels lead to a different electrochemical behaviour against corrosion, this effect together with the galvanic coupling with an unsensitised stainless steel may increase the corrosion processes undergone on the sensitised one.

Therefore, when unsensitised Alloy 900 is electrically coupled with sensitised samples, a concentration of anodic activity can be observed in the sensitised sample when the pairs are polarised at high potentials. Additionally, in all the cases the anodic member of the pair, i.e. the member with a more conductive passive film, is the sensitised Alloy 900 and this effect is greater for the steel heated at $850{ }^{\circ} \mathrm{C}$ for 2 hours. Furthermore, the 
sensitised area/unsensitised area ratio can enhance the formation of pits in the sensitised zones as a consequence of the galvanic effect if it is taken into consideration that the area of the sensitised zones in industrial facilities is smaller than the area of the unsensitised zones.

\section{Conclusions}

The main conclusions of this work can be summarised as follows:

1. Phase transformations in Alloy 900 can be observed in a confocal microscope as moving fronts of surface relief due to dilatometric changes and roughening as a result of the segregation of alloying elements. These fronts are generally observed inside the ferrite phase. Sigma and Chi phases along with areas depleted in alloying elements $(\mathrm{Cr}, \mathrm{Mo})$ appear when Alloy 900 is heated at $850{ }^{\circ} \mathrm{C}$.

2. The nucleation of the depleted areas leads to the formation of a more defective passive film with lower polarisation resistance and higher $\mathrm{N}_{\mathrm{D}}$ value, which increases the susceptibility to pit nucleation. These values are in agreement with the lower breakdown potential observed in the sensitised samples. Alloy 900 heated at $850{ }^{\circ} \mathrm{C}$ during 2 hours presents the highest $\mathrm{N}_{\mathrm{D}}$ and the lowest breakdown potential, being the most susceptible to the localised corrosion.

3. The effect of a more defective film (higher number of oxygen vacancies and lower polarisation resistance) is also observed in the SECM tests, where the oxygen consumption is greater on the sensitised samples than on the unsensitised Alloy 900.

4. The worse properties of the passive films due to the sensitisation are reflected too when samples of unsensitised and sensitised Alloy 900 are electrically coupled (LEIS measurements). The anodic member of the pair (higher admittance) is always the sensitised sample. This behaviour is more noticeable when higher potentials are applied. There is a point where the admittance of the unsensitised sample drops because of the breakdown of the passive film on the coupled sensitised specimen. 
5. Therefore, the sensitisation processes have a negative effect on the corrosion resistance of Alloy 900, degrading the protective properties of its passive film and increasing the susceptibility to pit formation. This effect can be enhanced as a consequence of the galvanic coupling between the unsensitised and sensitised samples and the unfavourable sensitised area/unsensitised area ratio.

Acknowledgments: We wish to express our gratitude to MICINN (CTQ2009-07518), to Universitat Politècnica de València (CEI-01-11), to the Generalitat Valenciana for its help in the CLSM acquisition (MY08/ISIRM/S/100), to Professor Alda Simoes and Andreia Marques for the help on LEIS measurements and to Dr. Asunción Jaime for her translation assistance.

\section{References}

[1] C.J. Park, V.Shankar Rao, H.S.Kwon. Effects of sigma phase on the initiation and propagation of pitting corrosion of duplex stainless steel. Corrosion 61 (2005), 76-83.

[2] Hozni M. Ezuber, A.El Houd, F.El-Shawesh. Effects of sigma phase precipitation on seawater pitting of Duplex stainless steel. Desalination 207 (2007), 268-275.

[3] M. Martins, L.C. Casteletti. Heat treatment temperature influence on ASTM A890 GR 6A superduplex stainless steel. Materials Characterization 55 (2005), 225-233.

[4] M. Pohl, O. Storz, T. Glogowski. Effect of intermetallics precipitations on the properties of duplex stainless steel. Materials Characterization 58 (2007), 65-71.

[5] Y.S. Sato, H. Kokawa. Preferential precipitation site of sigma phase in duplex stainless steel weld metal. Scripta Materialia 40 (1999), 659-663.

[6] N. Ortiz, F.F. Curiel, V.H. Lopez, A. Ruiz. Evaluation of the intergranular corrosion susceptibility of UNS S31803 duplex stainless steel with thermoelectric power measurements. Corrosion Science 69 (2013) 236-244.

[7] K.M. Lee, H. S. Cho, D. C. Choi. Effect of isothermal treatment of SAF 2205 duplex stainless steel on migration of / interface boundary and growth of austenite. Journal of Alloys and Compounds 285 (1999), 156-161.

[8] Hye-Jin Kim, Soon-Hyeok Jeon, Soon-Tae Kim, In-Sung Lee, Yong-Soo Park, Kwang-Tae Kim, Young-Sub Kim. Investigation of the sensitization and intergranular corrosion of tube-to-tubesheet welds of hyper duplex stainless steel using an electrochemical reactivation method. Corrosion Science 87(2014) 60-70.

[9] Jufeng Hong, Dong Han, Hua Tan, Jin Li, Yiming Jiang. Evaluation of aged duplex stainless steel UNS S32750 susceptibility to intergranular corrosion by optimized double loop electrochemical potentiokinetic reactivation method. Corrosion Science 68 (2013) 249-255.

[10] Tian Liang, Xiaoqiang Hu, Xiuhong Kang, Dianzhong Li. Effect of The Sigma Phase on the Mechanical Properties of a Cast Duplex Stainless Steel during the Ageing Treatment at 850 oC. Advanced Materials Research Vol. 684 (2013) 325329.

[11] T. Børvik, L.A. Marken, M. Langseth, G. Rørvik and O.S. Hopperstad. Influence of sigma-phase precipitation on the impact behaviour of duplex stainless steel pipe fittings. Ships and Offshore Structures, 2014.

[12] G. Fargas, A.Mestra,A.Mateo . Effect of sigma phase on the wear behavior of a super duplex stainless steel. Wear 303(2013) 584-590. 
[13] H. Yin, T. Emi, H. Shibata. Morphological instability of ä -ferrite/ ã -austenite interphase boundary in low carbon steels. Acta Materialia 47 (1999), 1523-1535.

[14] J. Lee, K. Shibata. K. Asakura. Y. Masumoto, Observation of g/a. transformation in Ultralow-carbon Steel under a High Temperature Optical Microscope. ISIJ Int 42 (2002), 1135-1143.

[15] J.E. Kittl, T.B. Massalski. A cinematographic study of the massive transformation in Cu/Ga alloys. Acta Metallurgica 15 (1967) 161-180., in 2014.

[16] E. Schmidt, Y. Wang, S. Sridhar. A Study of Nonisothermal Austenite Formation and Decomposition in Fe-C-Mn Alloys. Metall. Mater Trans A 37 (2006), 17991810.

[17] E. Schmidt, S. Sridhar. Proc. Solid-Solid Phase Transformations in inorganic materials 2005, Vol 1, ed. by J.M. Howe, TMS, Warrendale, PA, (2005) 551.

[18] E. Schmidt, D. Soltest, S. Roberts, A. Bednar, S. Sridhar. The austenite/ferrite front migration rate during Heating of IF steel. ISIJ International 46 (2006), 1500-1509.

[19] J. Sikora, E. Sikora, D. D Macdonald. The electronic structure of the passive film on tungsten. Electrochimica Acta 45 (2000) 1875-1883.

[20] KyungJin Park, SeJin Ahn, HyukSang Kwon. Effects of solution temperature on the kinetic nature of passive film on Ni. Electrochimica Acta 56 (2011) 16621669.

[21] Zhonglin Jiang, Xin Dai, Hugh Middleton. Investigation on passivity of titanium under steady-state conditions in acidic solutions. Materials Chemistry and Physics 126 (2011) 859-865.

[22] R. Badji, M. Bouabdallahb, B. Bacroix, C. Kahloun, B. Belkessa, H. Maza . Phase transformation and mechanical behavior in annealed 2205 duplex stainless steel welds. Materials characterization 59 (2008), 447-453.

[23] K.R. Kinsman, E. Eichen, H.I Aoroson. Thickening kinetics of proeutectoid ferrite plates in Fe-C alloys. Metall Trans A 29A (1975), 303-317.

[24] J.D. Watson, P.G. McDougall. The crystallography of widmanstätten ferrite. Acta Metallurgica 21 (1973) 961-973.

[25] H.M. Clark, C.M. Wayman. Phase transformations, ASM, Metals Park, OH, (1970), 59.

[26] H. Sieurin, R. Sandström. Sigma phase precipitation in duplex stainless steel 2005. Materials Science \& Engineering A 444 (2007), 271-276.

[27] J.S. Kim, H.S. Kwon. Effects of Tungsten on Corrosion and Kinetics of Sigma Phase Formation of 25\% Chromium Duplex Stainless Steels. Corrosion 55 (1999), 512-521.

[28] K.N.Adhe, V.Kain, K.Madangopal, and H.S.Gadiyar. Influence of Sigma -Phase Formation on the Localized Corrosion Behaviour of a Duplex Stainless steel. Journal of Materials Engineering and Performance 5 (2007), 500-506.

[29] P.R. Mei, A.A. Guimarães. Precipitation of carbides and sigma phase in AISI type 446 stainless steel under working conditions. Journal of Materials Processing Technology 155-156 (2004), 1681-1689.

[30] J. Michalska, M. Sozanska. Qualitative and quantitative analysis of Sigma and Chi phases in 2205 duplex stainless steel. Materials characterization 56 (2006), 355-362.

[31] K.H. Lo, C.H. Sheck, J.K.L. Lai. Recent developments in stainless steels. Materials Science and Engineering R 65 (2009), 39-104.

[32] J. Dobranszky, P.J. Szabo, T. Berecz, V. Hrotko, M. Portko. Energy-dispersive spectroscopy and electron backscatter diffraction analysis of isothermally aged 
SAF 2507 type superduplex stainless steel. Spectrochimica Acta Part B 59 (2004) 1781-1788.

[33] T.H. Chen, K.L. Weng, J.R. Yang. The effect of high-temperature exposure on the microstructural stability and toughness property in a 2205 duplex stainless steel. Materials Science and Engineering A 338 (2002) 259-270.

[34] M.E. Wilms, V.J. Gadgil, J.M. Krougman, F.P. Ijsseling. The effect of ó-phase precipitation at $800^{\circ} \mathrm{C}$ on the corrosion resistance in sea-water of a high alloyed duplex stainless steel. Corrosion Science 36 (1994) 871-875.

[35] M. Kaneko, and H.S. Isaacs. Pitting of stainless steel in bromide, chloride, and bromide/chloride solutions. Corrosion Science 42 (2000), 67-78.

[36] J. Stella, J. Cerezo, E. Rodríguez. Characterization of the sensitization degree in the AISI 304 stainless steel using spectral analysis and conventional ultrasonic techniques. NDT\&E international 42 (2009), 267-274.

[37] W. J. Lee, S. I. Pyun, J. W. Yeon, K. S. Chun, I. K. Choi, Electrochemical Methods in Corrosion Research Vi, Pts 1 and 2 289-2 (1998), 915.

[38] H. Shaikh, G. George, F. Shneider, K. Mummert, H. S. Khatak, Effect of high temperature aging on the corrosion behaviour of nitrogen added AISI type 316 stainless steel weld metal. Transactions of the Indian Institute of Metals 54, 27-39 (2001).

[39] H. Shaikh, B.P.C. Rao, S. Gupta, R.P. George, S. Venugopal, B. Sasi, T. Jayakumar, H.S. Khatak. Assessment of intergranular corrosion in AISI Type 316L stainless steel weldments. British Corrosion Journal 37 (2002), 129-140.

[40] Darlene Yuko Kobayashi, Stephan Wolynec. Evaluation of Low Corrosion resistance phase formed During the Sigma Phase Precipitation in Duplex Stainless Steels. Materials Research 2 (1999). 239-247.

[41] Ying Han, De Ning Zou, Wei Zhang, Jun Hui Yu, Yuan Yuan Qiao Influence of Sigma Phase Precipitation on Pitting Corrosion of 2507 Super-Duplex Stainless Steel. Materials Science Forum 658 (2010), 380-383.

[42] N.E. Hakiki, S. Boudin, B. Rondot, M. Da Cunha Belo, The electronic structure of passive films formed on stainless steels, Corrosion Science 37 (1995) 18091822.

[43] J. Pan, C. Leygraf, R.F.A. Jargelius-Pettersson, J. Linden, Characterization of high temperature oxide films on stainless steels by electrochemical-impedance spectroscopy, Oxid. Met. 50 (1998), 431-455.

[44] M. Da Cunha Belo, N.E. Hakiki, M.G.S. Ferreira. Semiconducting properties of passive films formed on nickel-base alloys type Alloy 600: influence of the alloying elements, Electrochimica Acta 44 (1999) 2473-2481.

[45] M.F. Montemor, M.G.S. Ferreira, N.E. Hakiki, M. Da Cunha Belo. Chemical composition and electronic structure of the oxide films formed on $316 \mathrm{~L}$ stainless steel and nickel based alloys in high temperature aqueous environments, Corrosion Science 42 (2000) 1635.1650.

[46] M.G.S. Ferreira, N.E. Hakiki, G. Goodlet, S. Faty, A.M.P. Simoes, M. Da Cunha Belo, Influence of the temperature of film formation on the electronic structure of oxide films formed on 304 stainless steel, Electrochimica Acta 46 (2001) 37673776.

[47] H.H. Ge, G.D. Zhou, W.Q. Wu, Passivation model of 316 stainless steel in simulated cooling water and the effect of sulfide on the passive film, Applied Surface Science 211 (2003) 321-334. 
[48] G. Rondelli, P. Torricelli, M. Fini, R. Giardino. In vitro corrosion study by EIS of a nickel-free stainless steel for orthopaedic applications, Biomaterials 26 (2005), 739-744.

[49] R.M. Fernández-Domene, E. Blasco-Tamarit,D.M. García-García. J. García Antón. Effect of alloying elements on the electronic properties of thin passive films formed on carbon steel, ferritic and austenitic stainless steels in a highly concentrated LiBr solution. Thin Solid Films 558 (2014) 252-258.

[50] J. Gao, Y. Jiang, B. Deng, W. Zhang, C.Zhong, Jin Li. Investigation of selective corrosion resistance of aged lean duplex stainless steel 2101 by non-destructive electrochemical techniques. Electrochimica Acta 54 (2009), 5830-5835.

[51] Yao Fu, Xinqiang Wu, En-Hou Han, Wei Ke, Ke Yang, Zhouhua Jiang. Effects of cold work and sensitization treatment on the corrosion resistance of high nitrogen stainless steel in chloride solutions. Electrochimica Acta 54 (2009), 1618-1629.

[52] M.Terada, D.M. Escriba, I. Costa, E. Materna-Morris, A.F. Padilha. Investigation on the intergranular corrosion resistance of the AISI 316L(N) stainless steel after long time creep testing at $600{ }^{\circ} \mathrm{C}$. Materials Characterization 59 (2008), 663-668.

[53] C. Valero Vidal, A. Igual Munoz. Study of the adsorption process of bovine serum albumin on passivated surfaces of CoCrMo biomedical alloy, Electrochimica Acta 55 (2010) 8445-8452.

[54] S. Luiz de Assis, S. Wolynec, I. Costa, Corrosion characterization of titanium alloys by electrochemical techniques, Electrochimica Acta 51 (2006) 1815-1819.

[55] A. Igual-Munoz, J. Garcia-Anton, J.L. Guinon, V. Perez-Herranz, Inhibition effect of chromate on the passivation and pitting corrosion of a duplex stainless steel in $\mathrm{LiBr}$ solutions using electrochemical techniques, Corrosion Science 49 (2007) 3200-3225.

[56] J. Pan, D. Thierry, C. Leygraf, Electrochemical impedance spectroscopy study of the passive oxide film on titanium for implant application, Electrochimica Acta 41 (1996) 1143-1153, in 2014.

[57] R.M. Fernandez-Domene, E. Blasco-Tamarit, D.M. García-García J. GarcíaAntón. Thermogalvanic corrosion of Alloy 31 in different heavy brine LiBr solutions. Corrosion Science 55 (2012), 40-43.

[58] J. Pan, D. Thierry, C. Leygraf, Electrochemical impedance spectroscopy study of the passive oxide film on titanium for implant application, Electrochimica Acta 41 (1996) 1143.1153.

[59] F. Mansfeld, M.W. Kendig, Evaluation of anodized aluminum surfaces with electrochemical impedance spectroscopy, J. Electrochemical Society 135 (1988) 828-833.

[60] R.M. Fernández-Domene, R. Sánchez-Tovar, C. Escrivà-Cerdán, R. Leiva-García, J. García-Antón. Study of passive films formed on AISI 316L stainless steel in non-polluted and underwater-volcano-polluted seawater. Corrosion 70 (2014) 390-401.

[61] N.E. Hakiki, M. Da Cunha Belo, A. M. P. Simões and M.G.S. Ferreira. Semiconducting Properties of Passive Films Formed on Stainless Steels Influence of the Alloying Elements. J. Electrochemical Society 145 (1998) 3821-3829.

[62] Y.X. Qiao, Y.G. Zheng, W. Ke, P.C. Okafor. Electrochemical behaviour of high nitrogen stainless steel in acidic solutions. Corrosion Science 51 (2009) 979-986.

[63] K. Uosaki, H. Kita. Effects of the Helmholtz Layer Capacitance on the Potential Distribution at Semiconductor/Electrolyte Interface and the Linearity of the MottSchottky Plot. J. Electrochemical Society 130 (1983) 895-897. 
[64] M. Parrinello, A. Rahman. Polymorphic transitions in single crystals: A new molecular dynamics method J. Applied Physics 52 (1981) 808-810.

[65] Agatino Di Paola. Semiconducting properties of passive films on stainless steels. Electrochimica Acta 34 (1989) 203-210.

[66] T.L.S Wijesinghe, D.J. Blackwood. Photocurrent and capacitance investigations into the nature of the passive films on austenitic stainless steels, Corrosion Science 50 (2008) 23-34.

[67] Z. Feng, X. Cheng, C.Dong, L. Xu, X. Li Passivity of $316 L$ stainless steel in borate buffer solution studied by Mott-Schottky analysis, atomic absorption spectrometry and X-ray photoelectron spectroscopy. Corrosion Science 52 (2010) 3646-3653.

[68] S. U.M. Khan, W. Schmickler. The capacity of thin passive films. Journal of Electroanalytical Chemistry and Interfacial Electrochemistry, 108 (1980), p. 329334.

[69] T.L.S Wijesinghe, D.J. Blackwood. Electrochemical and Photoelectrochemical Characterization of the Passive Film Formed on AISI 254SMO Super-Austenitic Stainless Steel J. Electrochemical Society 154 (2007) C16-C23.

[70] R.M. Fernández-Domene, E. Blasco-Tamarit, D.M. García-García, J. GarcíaAntón. Passive and transpassive behaviour of Alloy 31 in a heavy brine $\mathrm{LiBr}$ solution. Electrochimica Acta 95 (2013) 1-11.

[71] D.D. MacDonald. The Point Defect Model for the Passive State. J. Electrochemical Society 139 (1992) 3434-3449.

[72] D.D. Macdonald. Passivity-the key to our metals-based civilization. Pure Appl. Chem. 71 (1999): 951-978.

[73] J. Izquierdo, L. Martín-Ruíz, B.M. Fernández-Pérez, L. Fernández-Mérida, J.J. Santana, R.M. Souto. Imaging Local Surface Reactivity on Stainless Steels 304 and 316 in Acid Chloride Solution using Scanning Electrochemical Microscopy and the Scanning Vibrating Electrode Technique. Electrochimica Acta 134 (2014) 167-175.

[74] A.C. Bastos, A.M. Simões, S. González, Y. González-García, R.M. Souto, Imaging concentration profiles of redox-active species in open-circuit corrosion processes with the scanning electrochemical microscope. Electrochemistry Communications 6 (2004) 1212-1215.

[75] R. Leiva García, R. Akid, D. Greenfield, J. Gittens, J. García-Antón, M.J. MuñozPortero. Study of the sensitisation of a highly alloyed austenitic stainless steel, Alloy 926 (UNS N08926), by means of scanning electrochemical microscopy. Electrochimica Acta 70 (2012), 105-111.

[76] N. Le Bozec, C. Compère, M. L’Her, A. Laoueman, D. Costa, P. Marcus. Influence of stainless steel surface treatment on the oxygen reduction reaction in seawater Corrosion Science 43 (2001) 765-786.

[77] S.L.J. Gojkovic, S.K. Zecevic, M.D. Obradovic, D.M. Drazic. Oxygen reduction on a duplex stainless steel. Corrosion Science 40 (1998) 849-860.

[78] E.J. Calvo D.J. Schiffrin. Calvo. The reduction of hydrogen peroxide on passive iron in alkaline solution. J. Electroanalytical Chemistry 163 (1984) 257-275.

[79] S. Zecevic, D.M. Drazic, S.Lj. Gojkovic. Oxygen reduction on iron. Part III. An analysis of the rotating disk electrode measurements in near neutral solutions. J. Electroanalytical Chemistry 265 (1989) 179-193.

[80] N. Ramasubramanian, N. Preocanin, R.D. Davidson. Analysis of passive films on stainless steel by cyclic voltammetry and Auger spectroscopy. J. Electrochemical Society 132 (1985) 793-798., in 2014. 
[81] A.A. Sagüés, S.Virtanen and P. Schmuki. Oxygen Reduction on Passive Steel and $\mathrm{Cr}$ Rich Alloys for Concrete Reinforcement. "Passivation of Metals and Semiconductors, and Properties of Thin Oxide Layers", Philippe Marcus and Vincent Maurice, Eds., Elsevier, Amsterdam (2006).

[82] G. Baril, C.Blanc, M.Keddam, N.Pébère. Local Electrochemical Impedance Spectroscopy Applied to the Corrosion Behavior of an AZ91 Magnesium Alloy. J. Electrochem.Soc 150 (2003) B488-B493.

[83] J-B. Jorcin, E.Aragon, C. Merlatti, N. Pèbère. Delaminated areas beneath organic coating: A local electrochemical impedance approach. Corrosion Science 48 (2006), 1779-1790.

[84] D. Snihirova, S. V. Lamaka, M.F. Montemor. SMART" protective ability of water based epoxy coatings loaded with $\mathrm{CaCO}_{3}$ microbeads impregnated with corrosion inhibitors applied on AA2024 substrates. Electrochimica Acta 83 (2012), 439447.

[85] I.Annergren, F.Zou, D.Thierry. Application of localised electrochemical techniques to study kinetics of initiation and propagation during pit growth. Electrochimica Acta 44 (1999), 4383-4393.

[86] P. de Lima-Neto, J.P. Farias, L.F.G. Herculano, H. C. de Miranda, W.S. Araújo, JB. Jorcin, N. Pébère. Determination of the sensitized zone extension in welded AISI 304 stainless steel using non-destructive electrochemical techniques. Corrosion Science 50 (2008), 1149-1155.

\section{Table captions}

Table 1. Composition (\% weight) of the main alloying elements in the different phases observed in the tested specimens of Alloy 900.

Table 2. Electrochemical parameters obtained from the potentiodynamic curves carried out on Alloy 900 in its different sensitisation states in $1 \mathrm{mM} \mathrm{NaCl}$ solution at $25^{\circ} \mathrm{C}$.

Table 3. EIS parameters of Alloy 900 in its different sensitised states obtained after the fitting of the equivalent circuit to the data.

Table 4. Donor and acceptor densities for Alloy 900 in the $1 \mathrm{mM} \mathrm{NaCl}$ solution with different sensitisation degrees.

\section{Figure captions}

Figure 1. Schematic diagram of the working electrode tested in the different electrochemical techniques. Unsensitised sample on the rigth side.

Figure 2. CSLM images of the Alloy 900 surface during a heat treatment in inert atmosphere at $850{ }^{\circ} \mathrm{C}$ during 2 hours.

Figure 3. Roughness profiles of the Alloy 900 surface at different points of the heat treatment. 
Figure 4. SEM micrographs of the different Alloy 900 samples: unsensitised Alloy 900, sensitised Alloy 900 at $850{ }^{\circ} \mathrm{C}$ during 1 hour, and sensitised Alloy 900 at $850{ }^{\circ} \mathrm{C}$ during 2 hours. Images were obtained with backscattered electrons.

Figure 5. Percentage of phases on the studied specimens of Alloy 900. Unsensitised state, heated at $850^{\circ} \mathrm{C}$ during 1 hour and heated at $850^{\circ} \mathrm{C}$ during 2 hours.

Figure 6. Polarisation curves of Alloy 900 in the unsensitised state and in both studied sensitised states in a solution of $1 \mathrm{mM} \mathrm{NaCl}$ at $25^{\circ} \mathrm{C}$.

Figure 7. SEM micrograph of one sample of sensitised Alloy $900\left(850^{\circ} \mathrm{C}, 2 \mathrm{~h}\right)$ after the potentiodynamic curves. Some of the pits are indicated with red arrows.

Figure 8. Nyquist diagrams of the EIS measurements carried out with the samples at different potentials in the $1 \mathrm{mM} \mathrm{NaCl}$ solution at $25^{\circ} \mathrm{C}$.

Figure 9. Bode diagrams of the EIS measurements carried out with the samples at different potentials in the $1 \mathrm{mM} \mathrm{NaCl}$ solution at $25^{\circ} \mathrm{C}$.

Figure 10. Representation of the equivalent circuit used for a two-layer model of passive films and proposed for the interpretation of the EIS spectra.

Figure 11. Mott-Schottky plots for Alloy 900 in the $1 \mathrm{mM} \mathrm{NaCl}$ solution obtained at 5 $\mathrm{kHz}$ with different sensitisation degrees.

Figure 12. Cyclic voltammogram measured at the SECM tip immersed in the $1 \mathrm{mM}$ $\mathrm{NaCl}$ solution at $25^{\circ} \mathrm{C}$.

Figure 13. Approach curves carried out over the tested specimens in the $1 \mathrm{mM} \mathrm{NaCl}$ solution at $25^{\circ} \mathrm{C}$.

Figure 14. Line scans carried out over the tested specimens in the $1 \mathrm{mM} \mathrm{NaCl}$ solution at $25^{\circ} \mathrm{C}$. The sensitised sample is on the right.

Figure 15. Admittance profiles at $2 \mathrm{~Hz}$, obtained at different potentials, for the pair unsensitised Alloy 900/Alloy 900 sensitised at $850^{\circ} \mathrm{C}$ for $1 \mathrm{~h}$ (sensitised sample on the right side)

Figure 16. Admittance profiles at $2 \mathrm{~Hz}$, obtained at different potentials, for the pair unsensitised Alloy $900 /$ Alloy 900 sensitised at $850^{\circ} \mathrm{C}$ for $2 \mathrm{~h}$ (sensitised sample on the right side)

Figure 17. Maximum admittances obtained on the different samples of Alloy 900 during the LEIS measurements in $1 \mathrm{mM} \mathrm{NaCl}$ solution at $25^{\circ} \mathrm{C}$. 


\begin{tabular}{|c|c|c|c|c|}
\hline Phase & Element & $\begin{array}{c}\text { Unsensitised } \\
\text { state }\end{array}$ & $\begin{array}{c}\text { Heated at } 850^{\circ} \mathrm{C} \text {, } \\
\text { 1h }\end{array}$ & $\begin{array}{c}\text { Heated at } 850^{\circ} \mathrm{C} \\
\text { 2h }\end{array}$ \\
\hline \multirow{3}{*}{ Ferrite } & $\operatorname{Cr}(\%)$ & 26.0 & 25.2 & 25.2 \\
\hline & Ni (\%) & 3.8 & 3.0 & 2.9 \\
\hline & Mo (\%) & 3.3 & 3.9 & 3.8 \\
\hline \multirow{3}{*}{ Austenite } & $\operatorname{Cr}(\%)$ & 23.6 & 22.2 & 22.0 \\
\hline & $\mathrm{Ni}(\%)$ & 5.5 & 5.9 & 5.8 \\
\hline & Mo (\%) & 2.5 & 2.6 & 2.6 \\
\hline \multirow{3}{*}{ Sigma } & $\operatorname{Cr}(\%)$ & -- & 29.1 & 28.5 \\
\hline & $\mathrm{Ni}(\%)$ & -- & 2.6 & 3.4 \\
\hline & Mo (\%) & -- & 7.4 & 6.4 \\
\hline \multirow{3}{*}{ Chi } & $\operatorname{Cr}(\%)$ & -- & 25.0 & 25.0 \\
\hline & Ni (\%) & -- & 2.5 & 2.5 \\
\hline & Mo (\%) & -- & 10.3 & 10.3 \\
\hline
\end{tabular}




\begin{tabular}{|l|c|c|c|c|}
\hline \multicolumn{1}{|c|}{ Material } & $\begin{array}{c}\mathbf{E}_{\mathbf{c o r r}}(\mathbf{m V} \mathbf{v s} \\
\mathbf{A g} / \mathbf{A g C l})\end{array}$ & $\begin{array}{c}\mathbf{E}_{\mathbf{p}} \mathbf{( m V ~ v s} \\
\mathbf{A g} / \mathbf{A g C l})\end{array}$ & $\begin{array}{c}\mathbf{i}_{\mathbf{p}} \\
\left(\mathbf{\mu A} \cdot \mathbf{c m}^{-2}\right)\end{array}$ & $\begin{array}{c}\mathbf{i}_{\mathbf{c l}} \\
\left(\mathbf{\mu A} \cdot \mathbf{c m}^{-\mathbf{2}}\right)\end{array}$ \\
\hline Unsensitised Alloy 900 & $-126 \pm 17$ & -- & $1.62 \pm 0.1$ & $29.5 \pm 4.6$ \\
\hline Sensitised Alloy 900 (850 $\left.{ }^{\circ} \mathrm{C} 1 \mathrm{~h}\right)$ & $-58 \pm 14$ & $1170 \pm 12$ & $1.68 \pm 0.1$ & $50.5 \pm 4.1$ \\
\hline Sensitised Alloy 900 (850 $\left.{ }^{\circ} \mathrm{C} 2 \mathrm{~h}\right)$ & $-83 \pm 20$ & $866 \pm 19$ & $1.73 \pm 0.2$ & $51.9 \pm 5.1$ \\
\hline
\end{tabular}




\begin{tabular}{|c|c|c|c|c|c|c|c|c|}
\hline & $\begin{array}{c}R_{\mathrm{s}} \\
\left(\mathrm{k} \Omega \cdot \mathrm{cm}^{2}\right)\end{array}$ & $\begin{array}{c}R_{1} \\
\left(\mathrm{k} \Omega \cdot \mathrm{cm}^{2}\right)\end{array}$ & $\mathbf{n}_{1}$ & $\begin{array}{c}\mathrm{C}_{1} \\
\left(\mu \mathrm{F} \cdot \mathbf{c m}^{-2}\right)\end{array}$ & $\begin{array}{c}R_{2} \\
\left(\mathrm{k} \Omega \cdot \mathrm{cm}^{2}\right)\end{array}$ & $\mathbf{n}_{2}$ & $\begin{array}{c}\mathrm{C}_{2} \\
\left(\mu \mathrm{F} \cdot \mathbf{c m}^{-2}\right)\end{array}$ & $\begin{array}{c}R_{\mathbf{P}} \\
\left(\mathrm{k} \Omega \cdot \mathrm{cm}^{2}\right)\end{array}$ \\
\hline \multicolumn{9}{|c|}{ Unsensitised Alloy 900} \\
\hline OCP & $0.79 \pm 0.01$ & $1.07 \pm 0.02$ & 0.81 & $11.2 \pm 0.3$ & $291.42 \pm 1.25$ & 0.80 & $15.00 \pm 0.4$ & $293.28 \pm 1.27$ \\
\hline $0.2 \mathrm{~V}$ vs Ag/AgCl & $0.83 \pm$ & $3.79 \pm 0.01$ & 0.85 & $6.05 \pm$ & $1881.00 \pm 11.17$ & 0.85 & $6.68=$ & 1885.61 \\
\hline $0.4 \mathrm{~V}$ vs $\mathrm{Ag} / \mathrm{AgCl}$ & $0.85=$ & $3.18=$ & 0.89 & $5.37 \pm 0.1$ & $3940.00 \pm 6.23$ & 0.86 & $5.78 \pm 0.3$ & 3944.00 \\
\hline $\mathrm{gCl}$ & 0.78 & .02 & 0.87 & 3.86 & 317 & 0.85 & 0.2 & 3172 \\
\hline $0.8 \mathrm{~V}$ vs $\mathrm{Ag} / \mathrm{AgCl}$ & $0.79 \pm 0.01$ & $1.17 \pm 0.01$ & 0.87 & $4.05 \pm 0.3$ & $2043.60 \pm 12.44$ & 0.80 & $7.06 \pm 0.5$ & $3172.25 \pm 12.76$ \\
\hline $1 \mathrm{~V}$ vs Ag/AgCl & $0.77 \pm 0.01$ & $0.81 \pm 0.01$ & 0.87 & 0.3 & $479.19 \pm 7.24$ & 0.82 & 0.3 & $2045.56 \pm 7.61$ \\
\hline \multicolumn{9}{|c|}{ Alloy 900 heated at $850^{\circ} \mathrm{C} 1$ hour } \\
\hline OCP & $0.76 \pm 0.01$ & 1.04 & 0.79 & $9.3 \pm 0.1$ & $159 .($ & 0.81 & $15.70 \pm 0.1$ & $160.84 \pm 7.35$ \\
\hline $0.2 \mathrm{~V}$ vs Ag/AgCl & $0.71 \pm 0.01$ & $1.41 \pm 0.09$ & 0.85 & $6.23 \pm 0.4$ & $953.29 \pm 12.26$ & 0.82 & $11.16 \pm 0.4$ & $945.40 \pm 12.98$ \\
\hline $0.4 \mathrm{~V}$ vs Ag/AgCl & $0.79 \pm 0.02$ & $1.34 \pm 0.03$ & 0.87 & $6.22 \pm 0.1$ & $1097.00 \pm 20.14$ & 0.81 & $8.34 \pm 0.5$ & $1099.13 \pm 20.25$ \\
\hline $0.6 \mathrm{~V}$ vs Ag/AgCl & $0.83 \pm 0.01$ & $1.30 \pm 0.04$ & 0.90 & $5.46 \pm 0.3$ & $744.56 \pm 14.25$ & 0.78 & $8.51 \pm 0.2$ & $746.11 \pm 14.29$ \\
\hline $0.8 \mathrm{~V}$ vs $\mathrm{Ag} / \mathrm{AgCl}$ & $0.83 \pm 0.01$ & $1.36 \pm 0.02$ & 0.87 & $5.98 \pm 0.1$ & $178.07 \pm 8.25$ & 0.81 & $10.65 \pm 0.2$ & $180.26 \pm 8.35$ \\
\hline $1 \mathrm{~V}$ vs Ag/AgCl & $0.83 \pm 0.01$ & $1.11 \pm 0.05$ & 0.87 & $6.94 \pm 0.2$ & $119.10 \pm 16.35$ & 0.70 & 1.1 & $120.94 \pm 16.41$ \\
\hline \multicolumn{9}{|c|}{ Alloy 900 heated at $850^{\circ} \mathrm{C} 2$ hours } \\
\hline OCP & $0.77 \pm 0.02$ & $1.02 \pm 0.16$ & 0.64 & $2.45 \pm 0.2$ & $139.9 \pm 12.13$ & 0.85 & $15.20 \pm 0.1$ & $141.69 \pm 12.33$ \\
\hline $0.2 \mathrm{~V}$ vs $\mathrm{Ag} / \mathrm{AgCl}$ & $0.89 \pm 0.01$ & 0.99 & 0.90 & 13.08 & 234. & 0.79 & 9.64 & 256.38 \\
\hline $0.4 \mathrm{~V}$ vs Ag/AgCl & $0.79 \pm 0.01$ & $0.99 \pm 0.08$ & 0.89 & $8.25 \pm 0.2$ & $349.2 \pm 7.38$ & 0.78 & $10.46 \pm 0.3$ & $350.98 \pm 7.52$ \\
\hline $0.6 \mathrm{~V}$ vs Ag/AgCl & $0.79 \pm 0.01$ & $0.80 \pm 0.06$ & 0.92 & $10.95 \pm 0.3$ & $341.2 \pm 8.15$ & 0.80 & $10.54 \pm 0.1$ & $342.79 \pm 8.22$ \\
\hline $0.8 \mathrm{~V}$ vs Ag/AgCl & $0.78 \pm 0.02$ & $0.82 \pm 0.23$ & 0.89 & $11.00 \pm 0.4$ & $7.8 \pm 1.15$ & 0.78 & $14.50 \pm 0.5$ & $9.40 \pm 1.40$ \\
\hline $1 \mathrm{~V}$ vs $\mathrm{Ag} / \mathrm{AgCl}$ & $0.71 \pm 0.05$ & $0.91 \pm 0.33$ & 0.89 & $11.71 \pm 0.7$ & $7.3 \pm 2.15$ & 0.7 & $16.08 \pm 1.3$ & $7.30 \pm 2.53$ \\
\hline
\end{tabular}




\begin{tabular}{|l|c|c|}
\hline & $\left.\mathbf{N}_{\mathbf{D}} \mathbf{x} \mathbf{1 0}^{\mathbf{2 1}} \mathbf{( c m}^{-\mathbf{3}}\right)$ & $\mathbf{N}_{\mathbf{A}} \mathbf{x} \mathbf{1 0}$ \\
\hline Unsensitised Alloy 900 & $0.885 \pm 0.09$ & $7.578 \pm 0.11$ \\
\hline Sensitised Alloy $900\left(850^{\circ} \mathrm{C} 1 \mathrm{~h}\right)$ & $1.205 \pm 0.10$ & $4.700 \pm 0.09$ \\
\hline Sensitised Alloy $900\left(850^{\circ} \mathrm{C} 2 \mathrm{~h}\right)$ & $4.639 \pm 0.12$ & $4.186 \pm 0.13$ \\
\hline
\end{tabular}




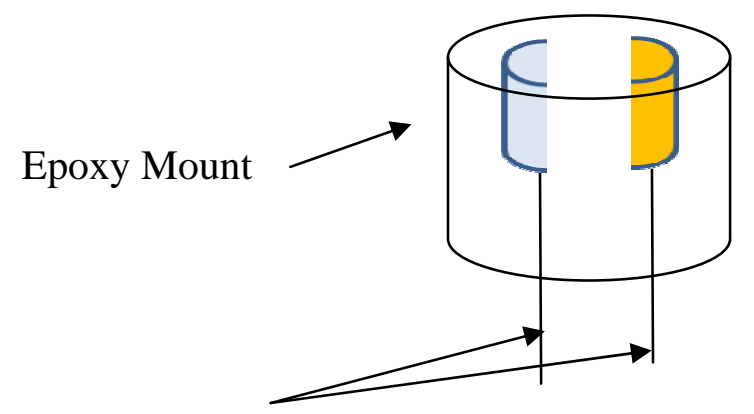

Electrical Connections 


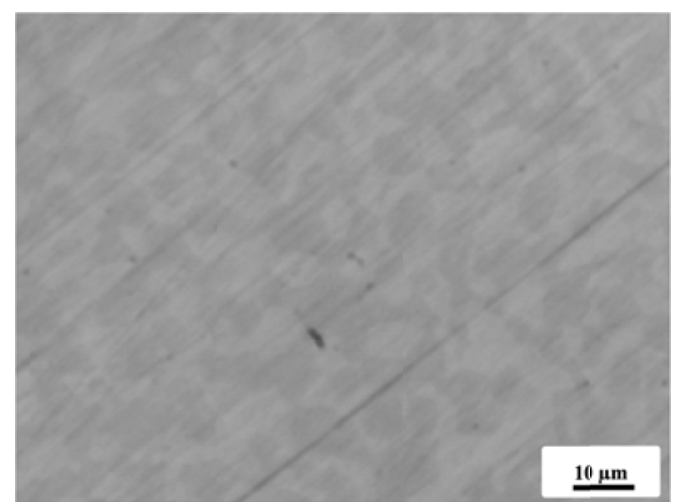

a) $500{ }^{\circ} \mathrm{C}$

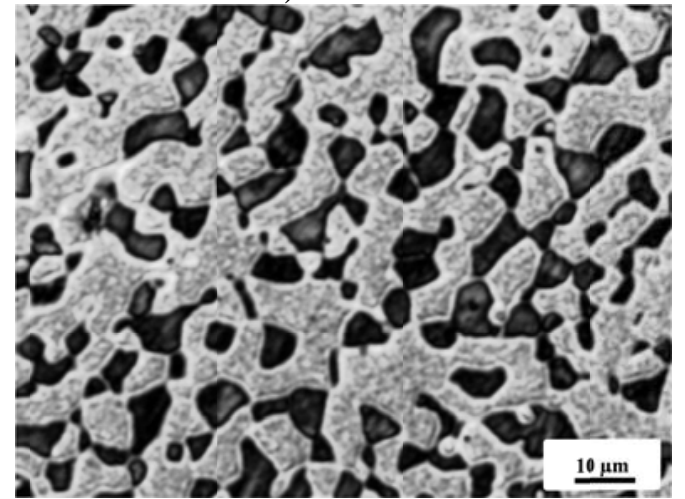

c) $813^{\circ} \mathrm{C}$

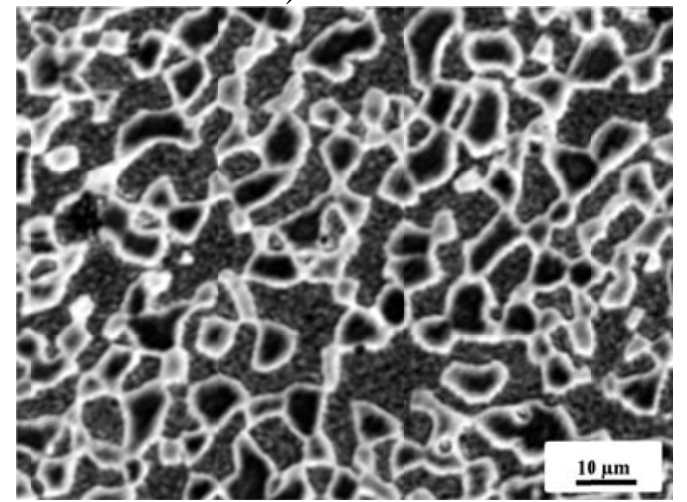

e) $850{ }^{\circ} \mathrm{C}$

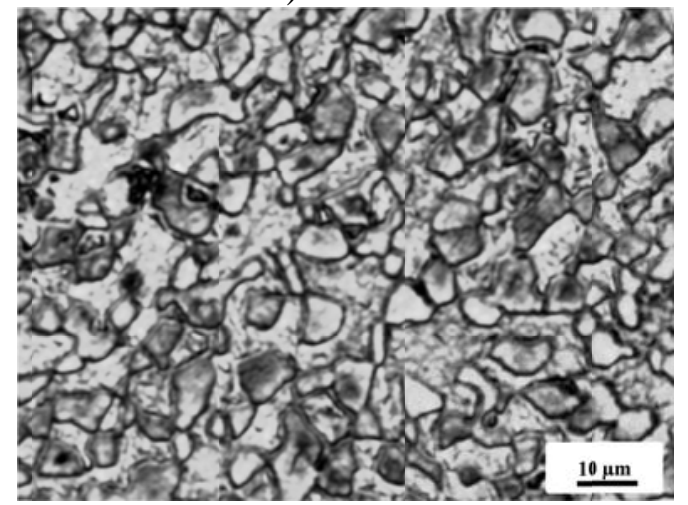

g) $850{ }^{\circ} \mathrm{C}, 40$ minutes

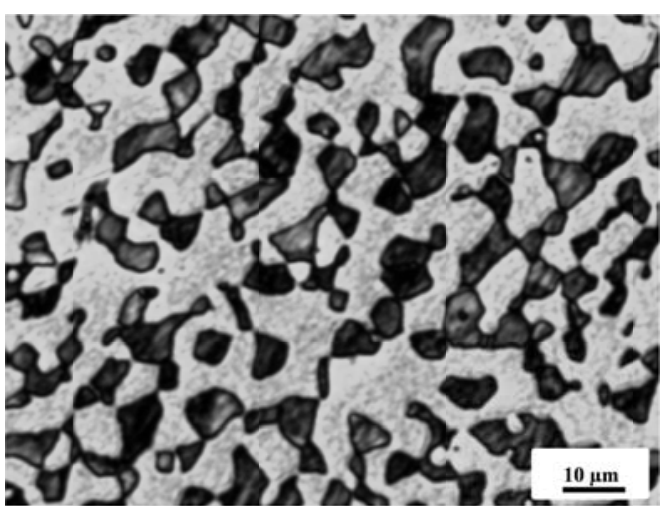

b) $780^{\circ} \mathrm{C}$

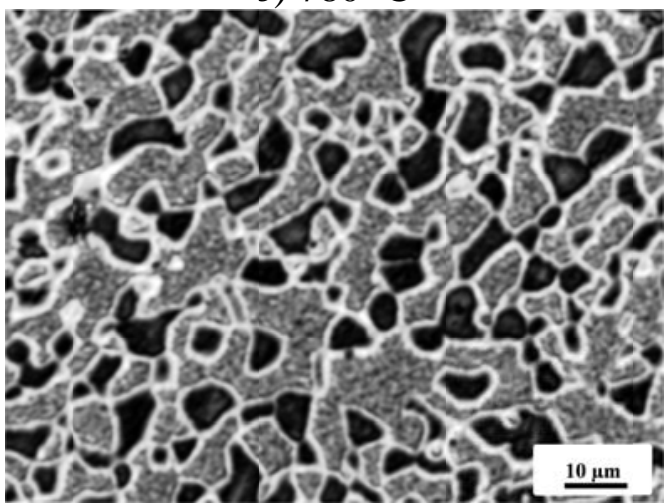

d) $840{ }^{\circ} \mathrm{C}$

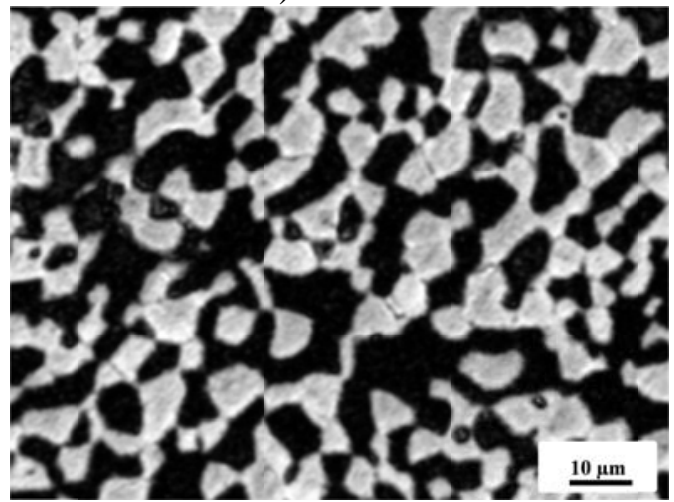

f) $850^{\circ} \mathrm{C}, 10$ minutes

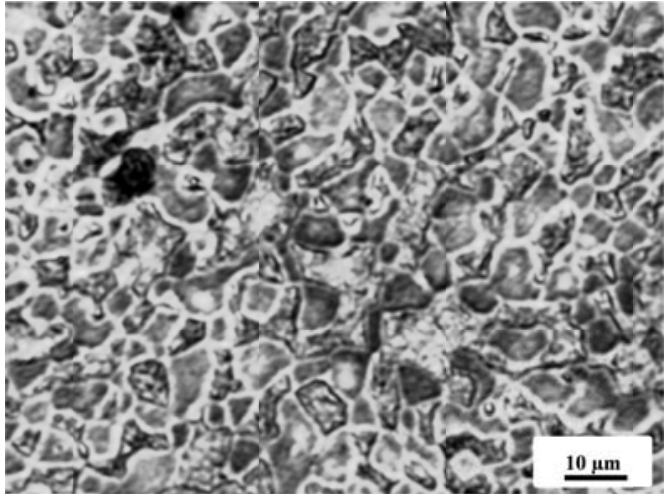

h) $850{ }^{\circ} \mathrm{C}, 120$ minutes 


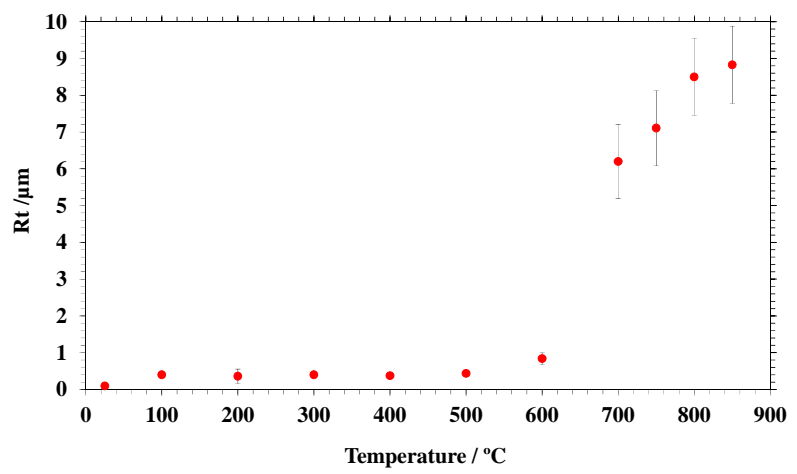

a) Roughness during the heating ramp

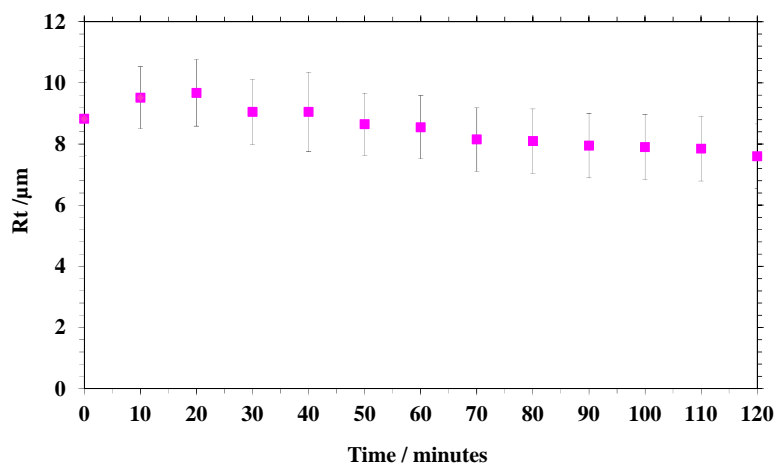

b) Roughness during the isothermal step $850{ }^{\circ} \mathrm{C}$ 


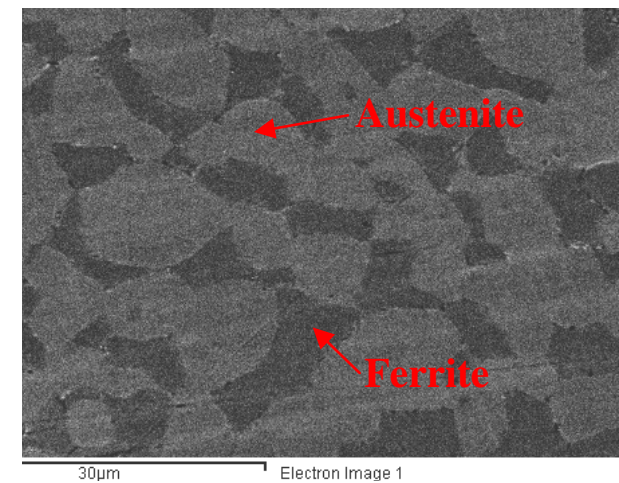

a) Unsensitised Alloy 900

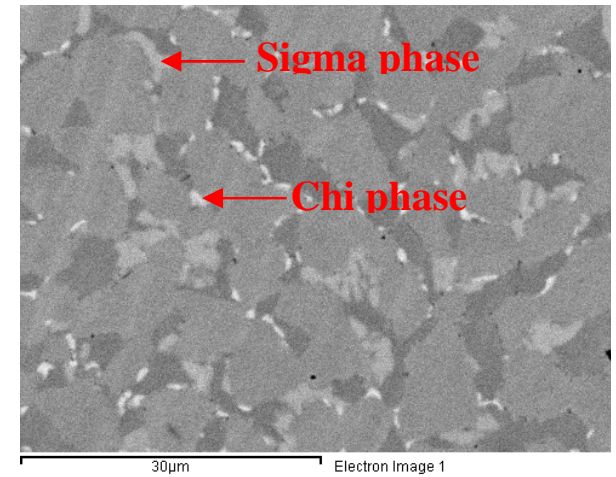

b) Alloy 900 heated at $850{ }^{\circ} \mathrm{C}$ during 1 hour

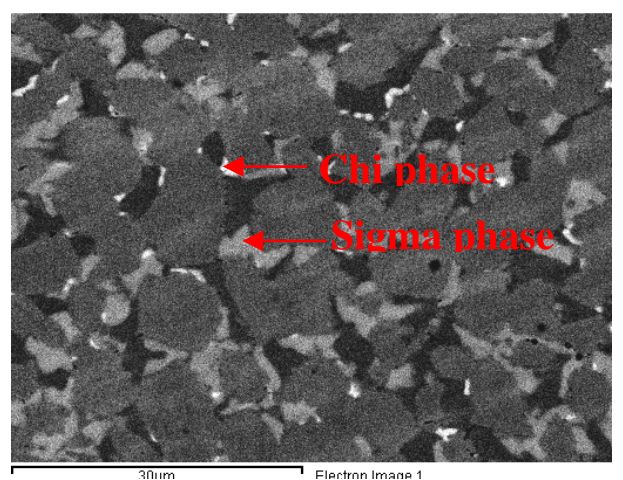

c) Alloy 900 heated at $850{ }^{\circ} \mathrm{C}$ during 2 hours 


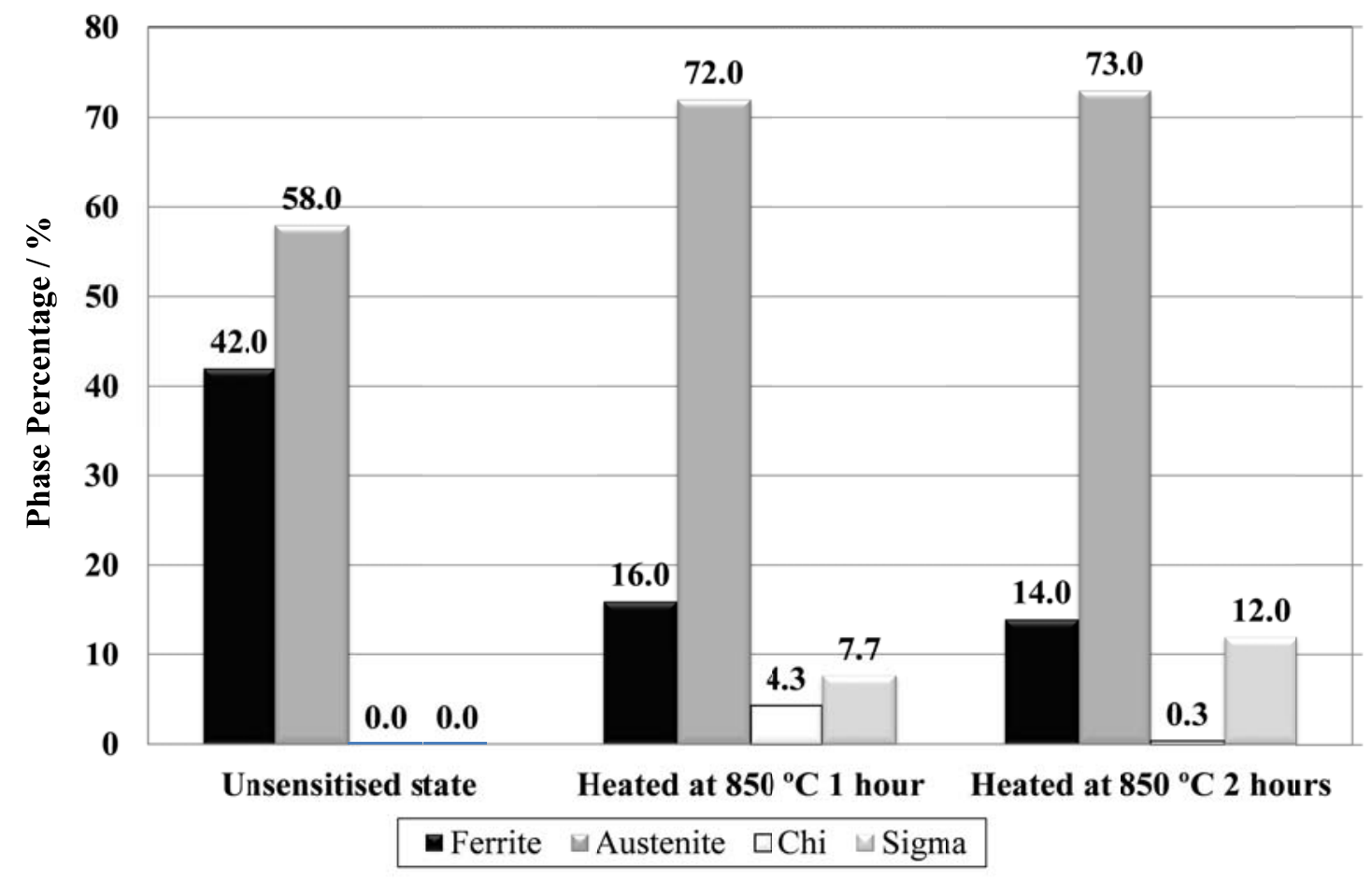




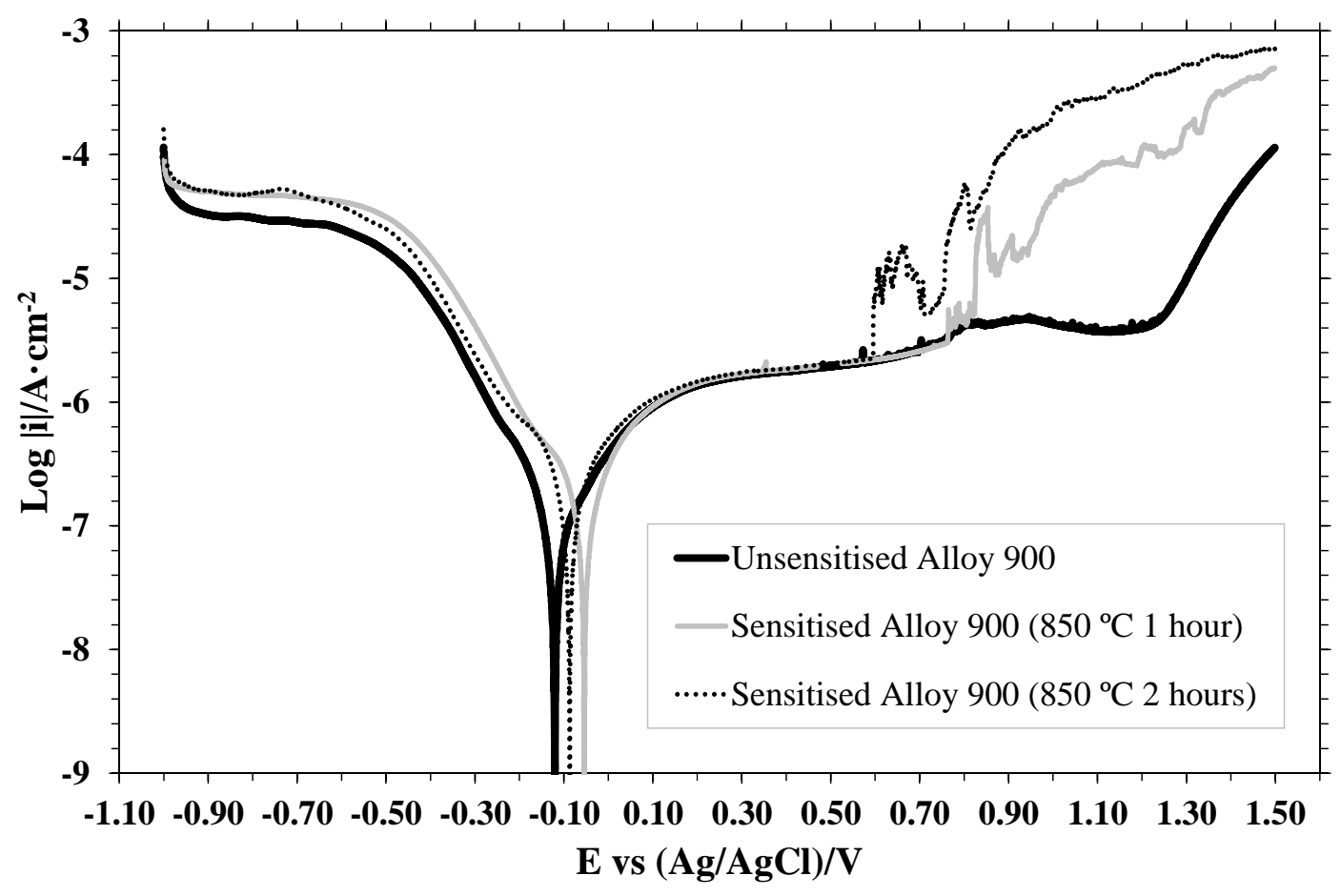




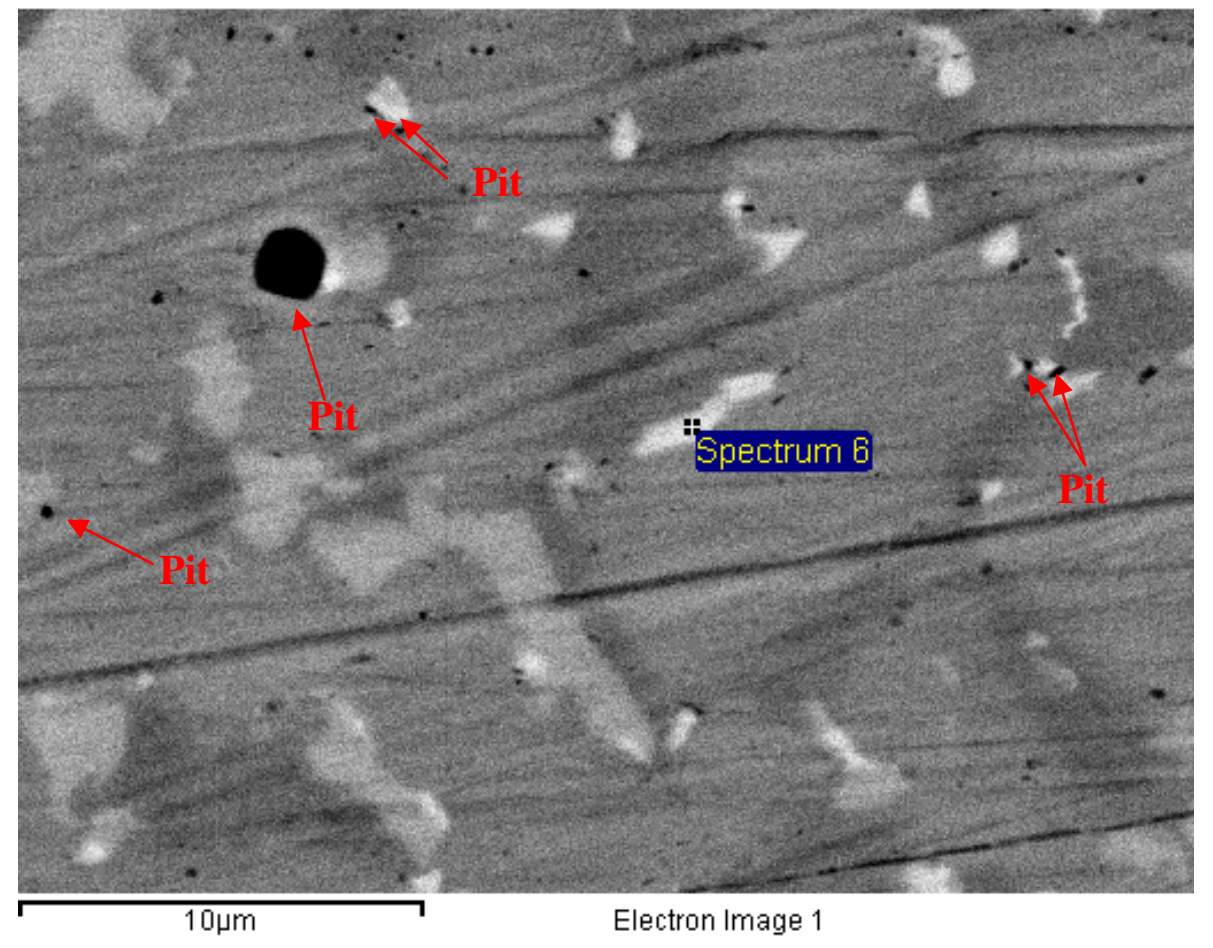




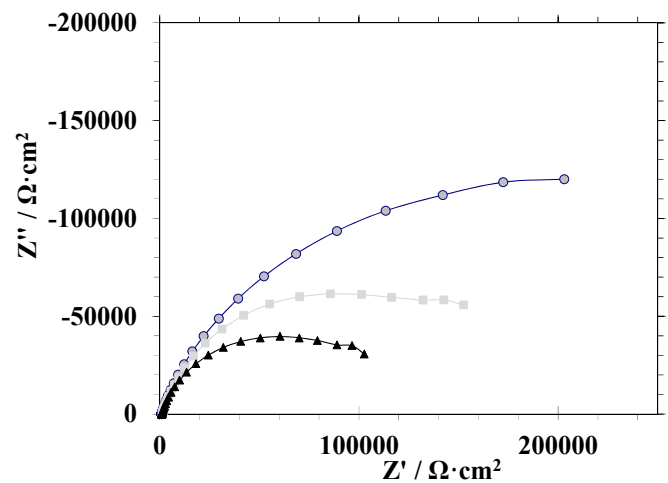

a) OCP

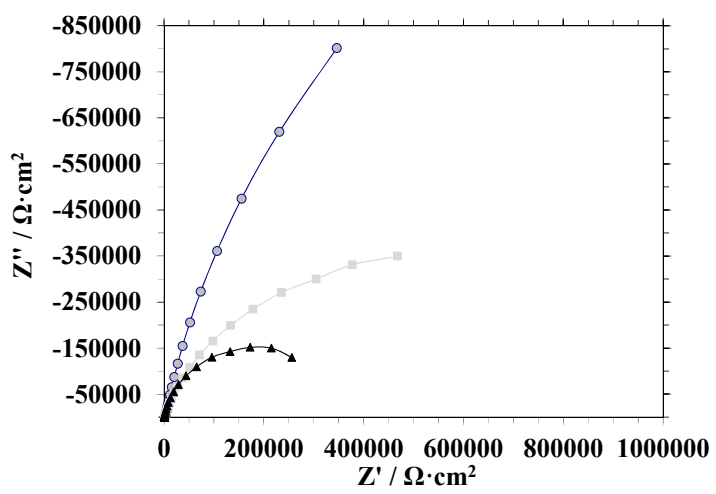

c) $0.4 \mathrm{~V}$ vs $\mathrm{Ag} / \mathrm{AgCl}$

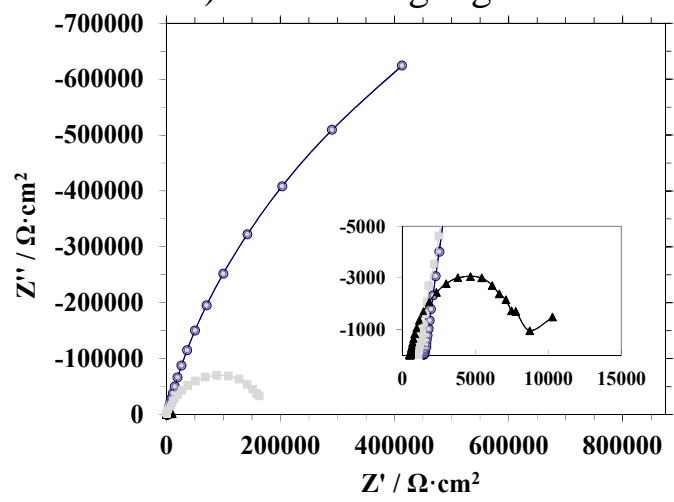

e) $0.8 \mathrm{~V}$ vs $\mathrm{Ag} / \mathrm{AgCl}$

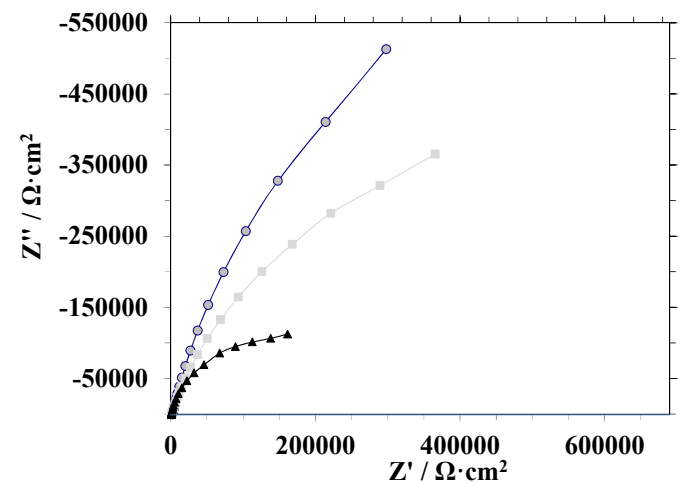

b) $0.2 \mathrm{~V}$ vs $\mathrm{Ag} / \mathrm{AgCl}$

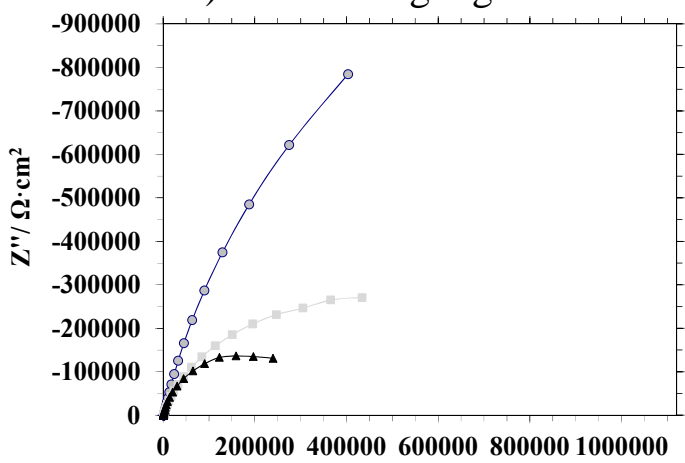

$$
\mathbf{Z}^{\prime} / \mathbf{\Omega} \cdot \mathbf{c m}^{2}
$$

d) $0.6 \mathrm{~V}$ vs $\mathrm{Ag} / \mathrm{AgCl}$

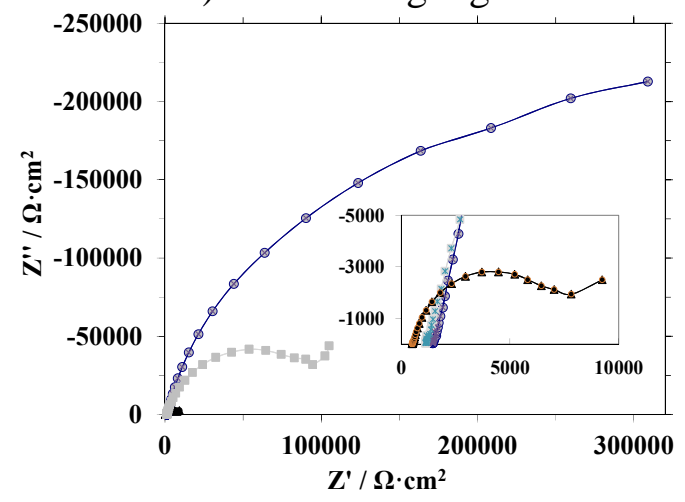

f) $1 \mathrm{~V}$ vs $\mathrm{Ag} / \mathrm{AgCl}$

○ Unsensitised Alloy $900-$ Alloy 900 heated at $850{ }^{\circ} \mathrm{C} 1 \mathrm{~h} \triangle$ Alloy 900 heated at $850{ }^{\circ} \mathrm{C} 2 \mathrm{~h}$ 


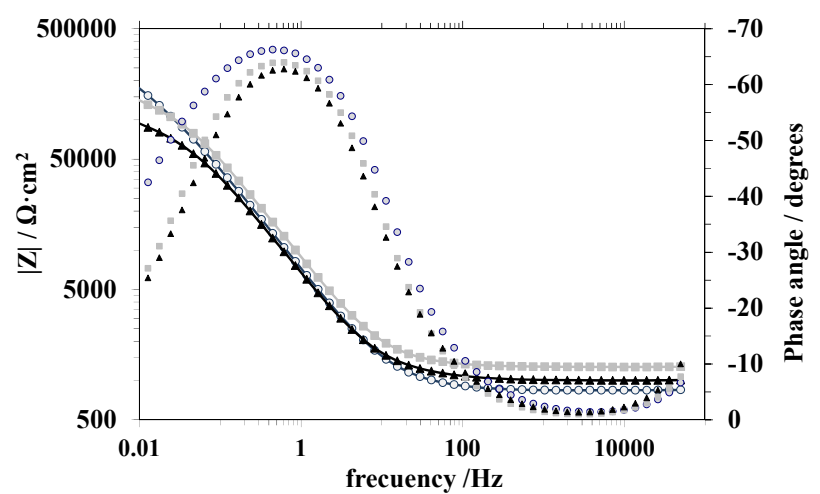

a) $\mathrm{OCP}$

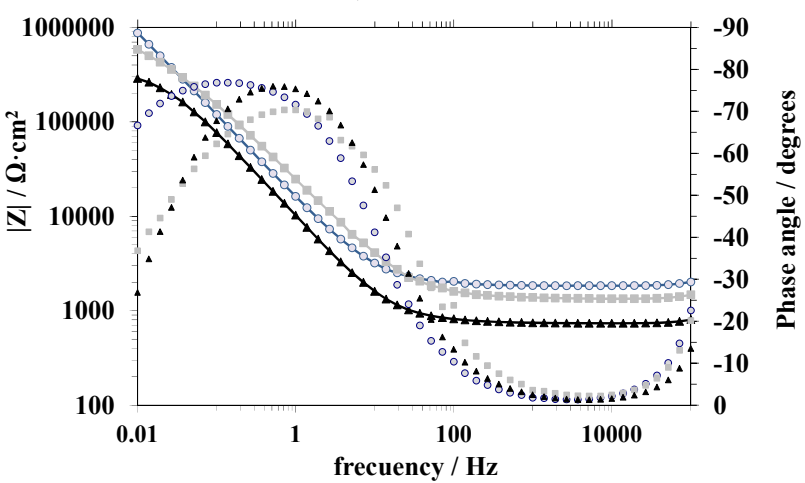

c) $0.4 \mathrm{~V}$ vs $\mathrm{Ag} / \mathrm{AgCl}$

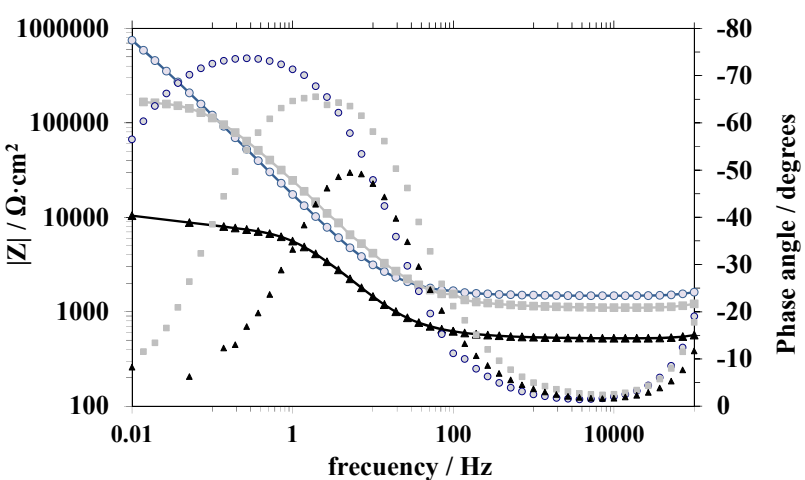

e) $0.8 \mathrm{~V}$ vs $\mathrm{Ag} / \mathrm{AgCl}$

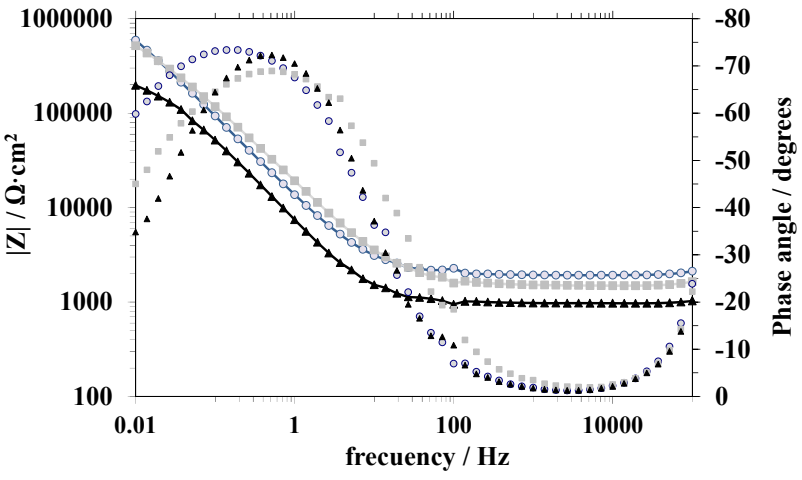

b) $0.2 \mathrm{~V}$ vs $\mathrm{Ag} / \mathrm{AgCl}$

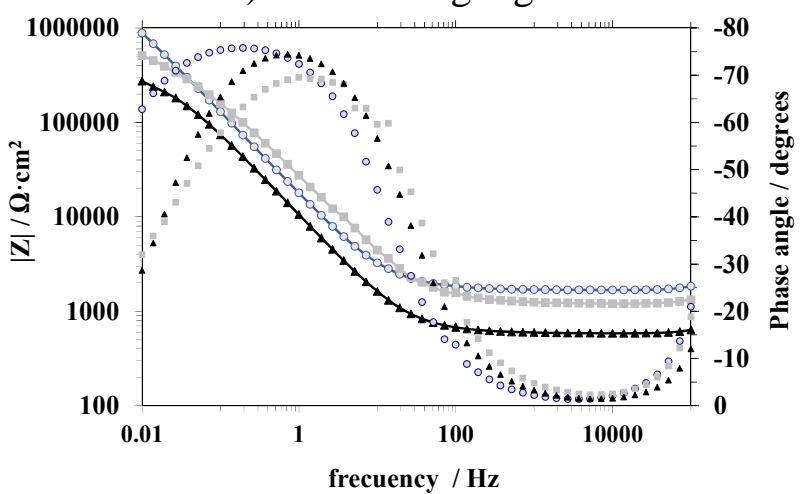

d) $0.6 \mathrm{~V}$ vs $\mathrm{Ag} / \mathrm{AgCl}$

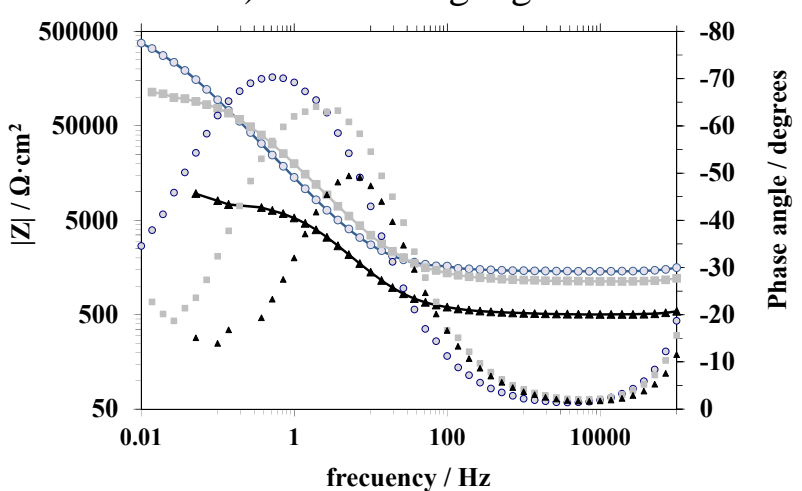

f) $1 \mathrm{~V}$ vs $\mathrm{Ag} / \mathrm{AgCl}$

○ Unsensitised Alloy $900-$ Alloy 900 heated at $850{ }^{\circ} \mathrm{C} 1 \mathrm{~h} \triangle$ Alloy 900 heated at $850{ }^{\circ} \mathrm{C} 2 \mathrm{~h}$ 


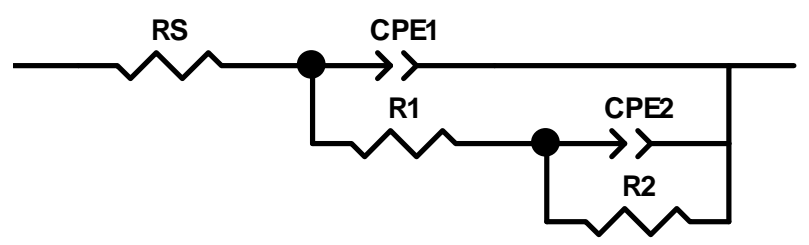




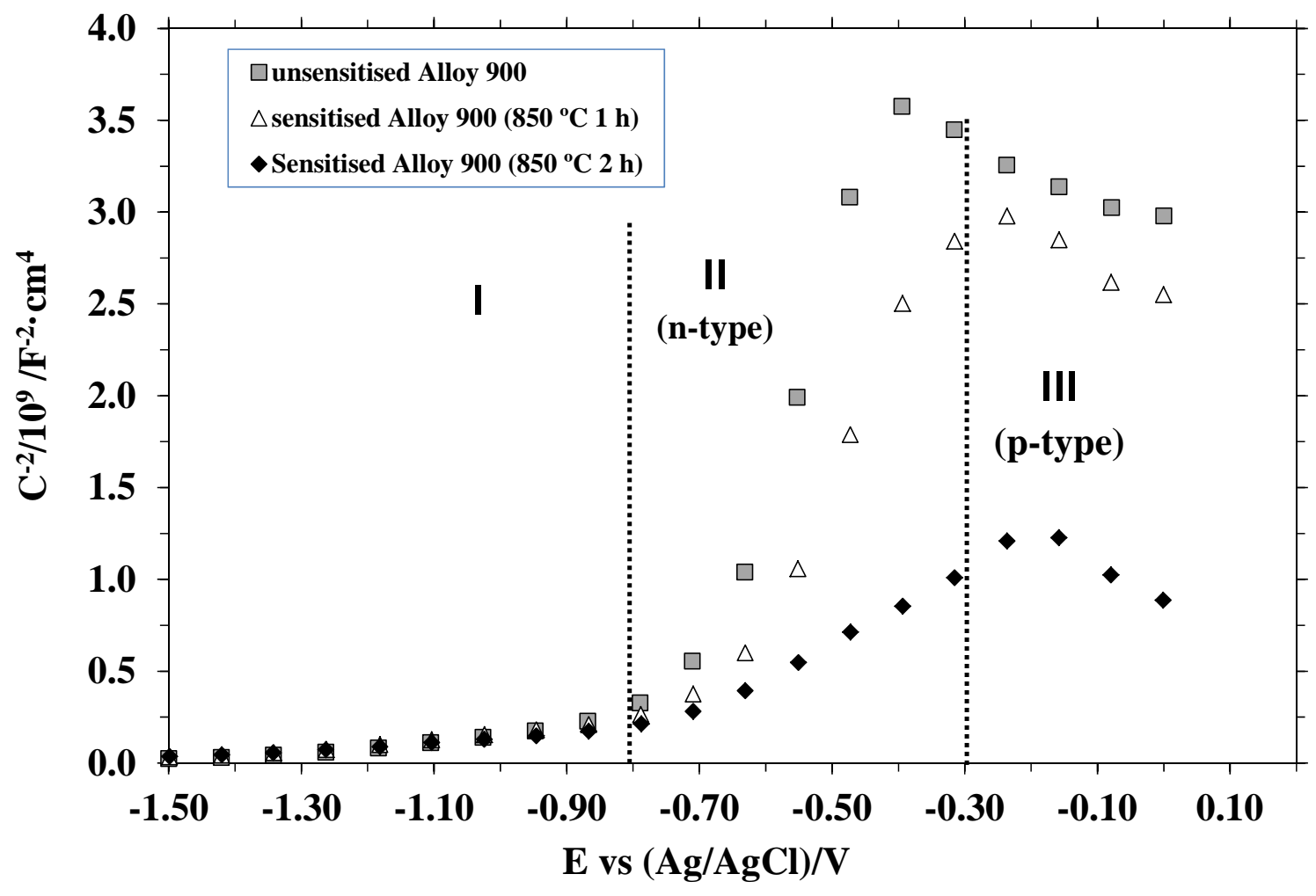




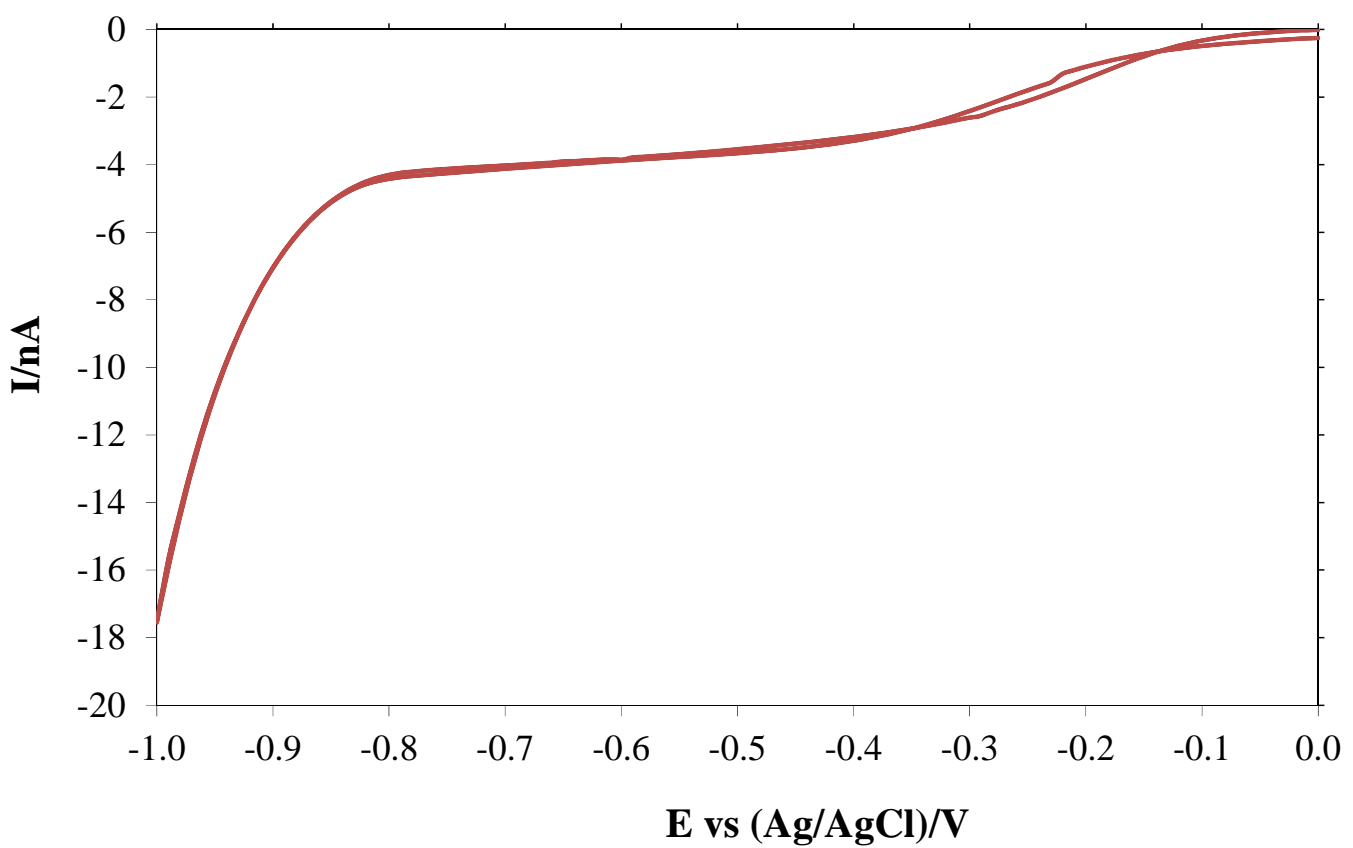




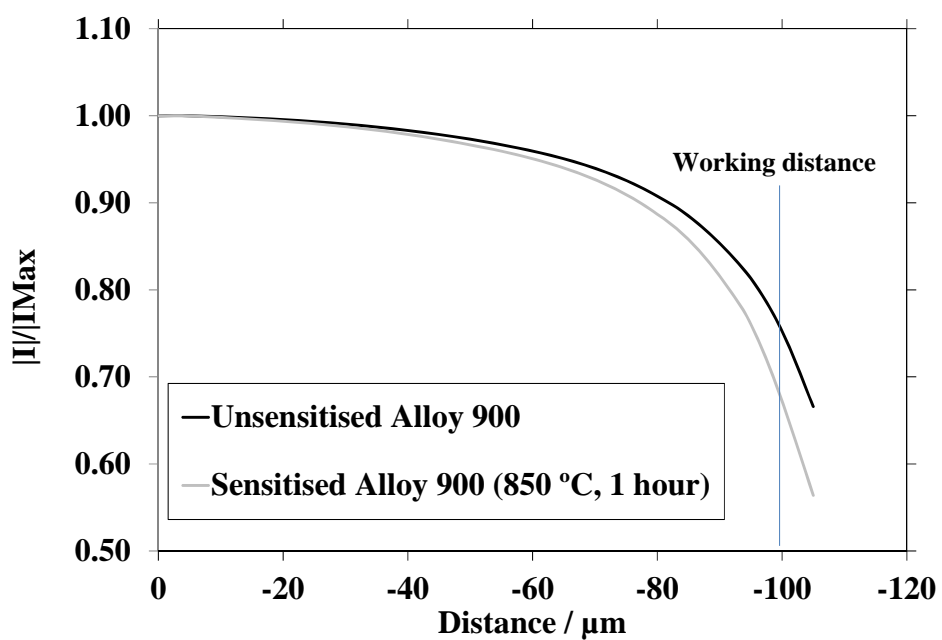

a) Alloy 900 heated at $850{ }^{\circ} \mathrm{C}$ during 1 hour

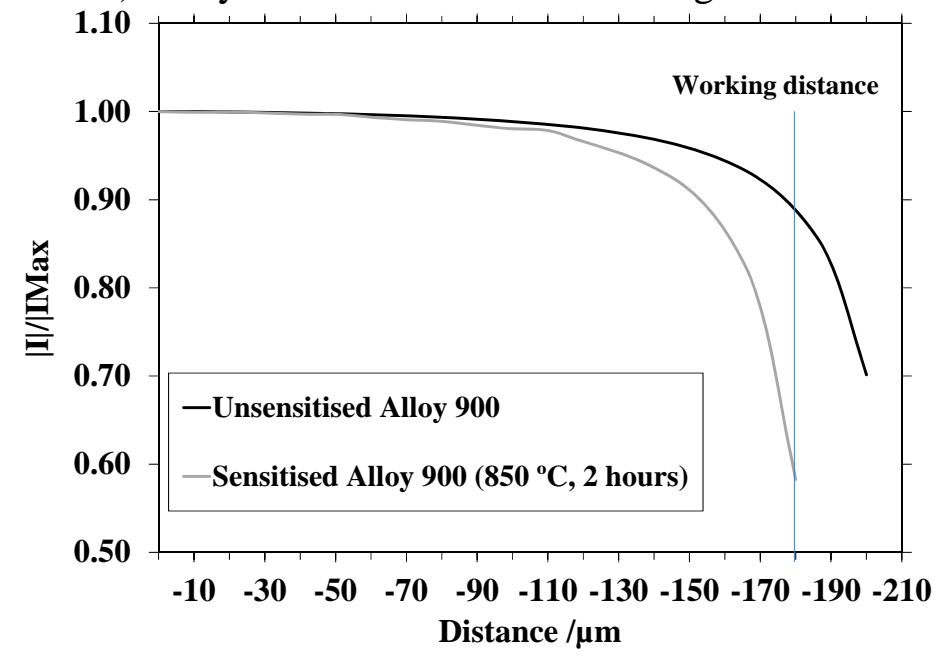

b) Alloy 900 heated at $850{ }^{\circ} \mathrm{C}$ during 2 hours 


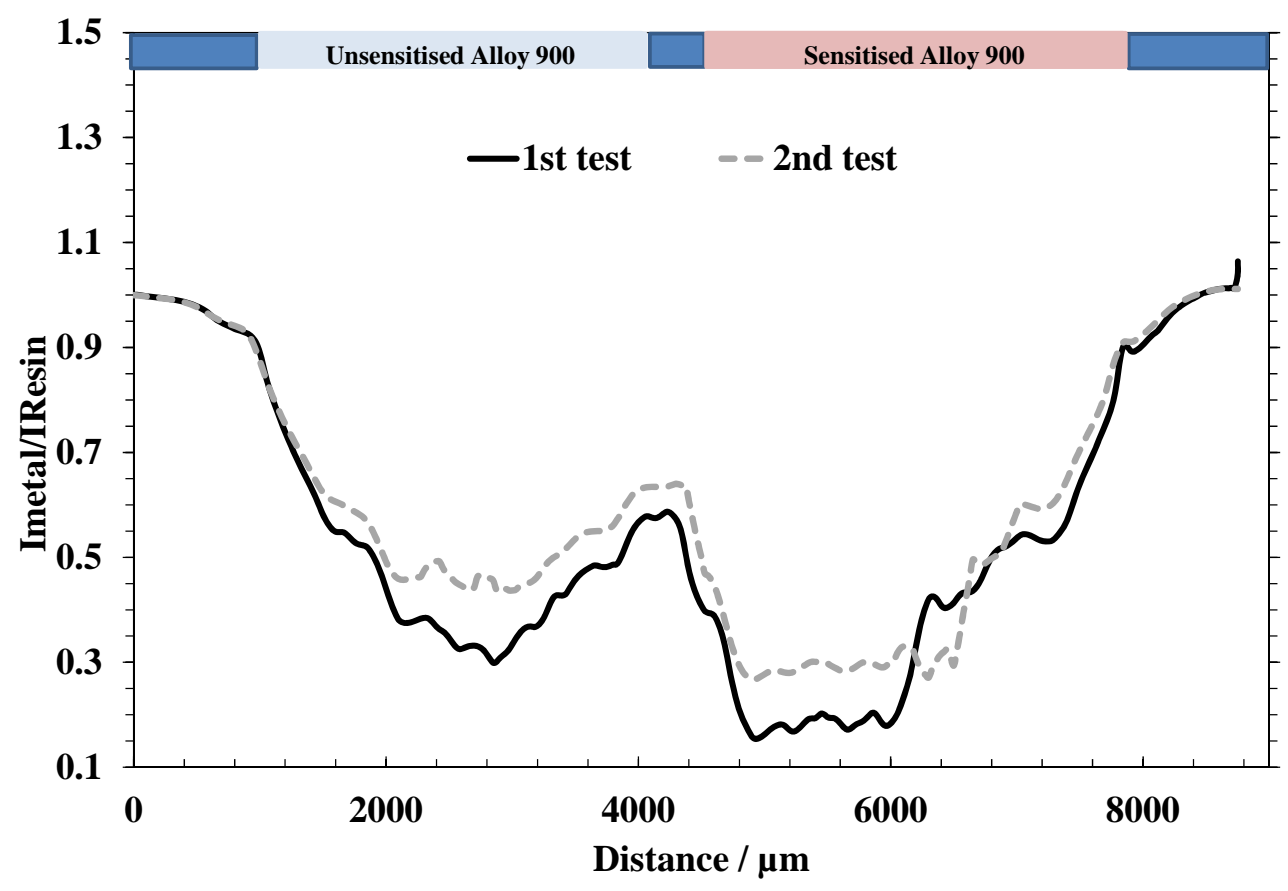

a) Alloy 900 heated at $850{ }^{\circ} \mathrm{C}$ during 1 hour

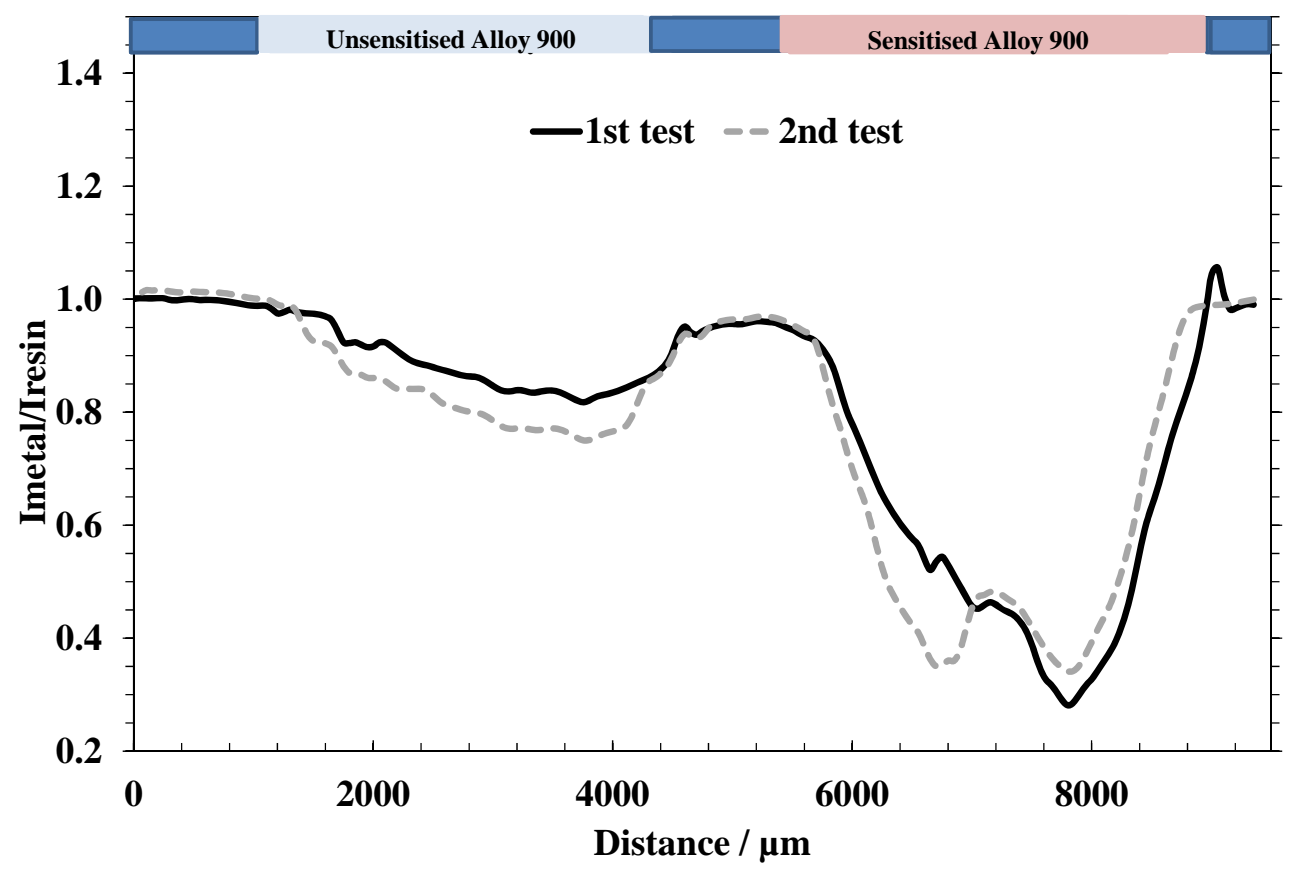

b) Alloy 900 heated at $850{ }^{\circ} \mathrm{C}$ during 2 hours 


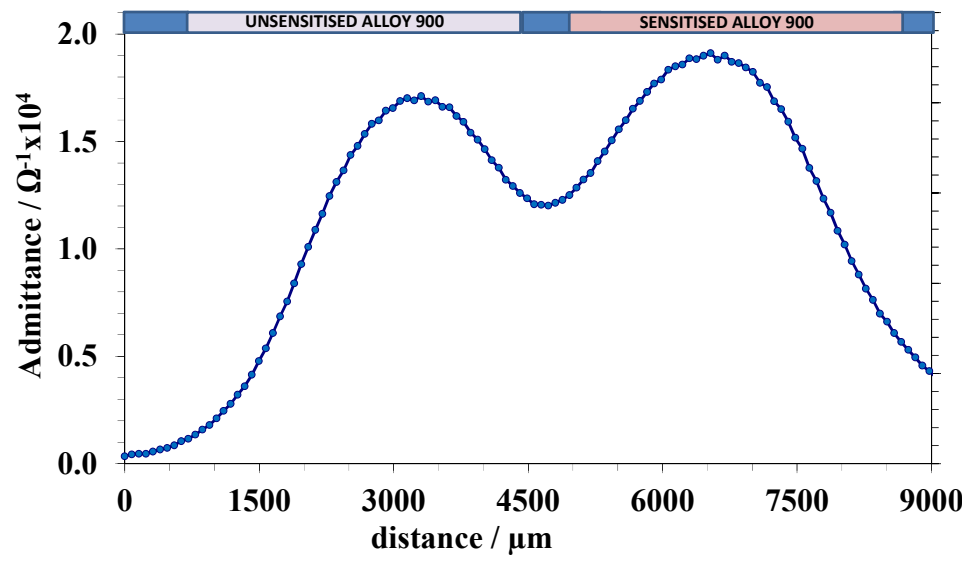

a) Admittance profiles at Open Circuit Potential

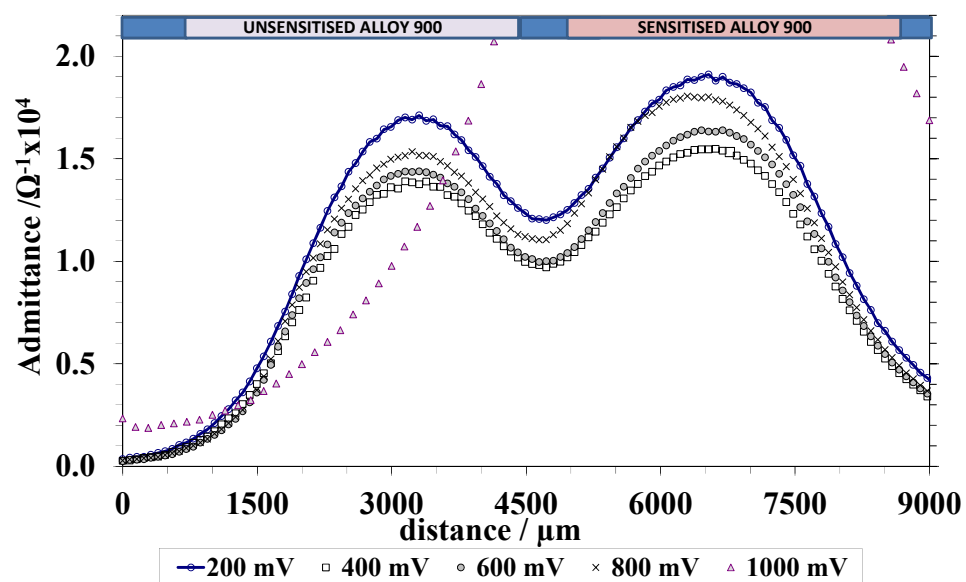

c) Admittance profiles at different imposed potentials. (Magnification)

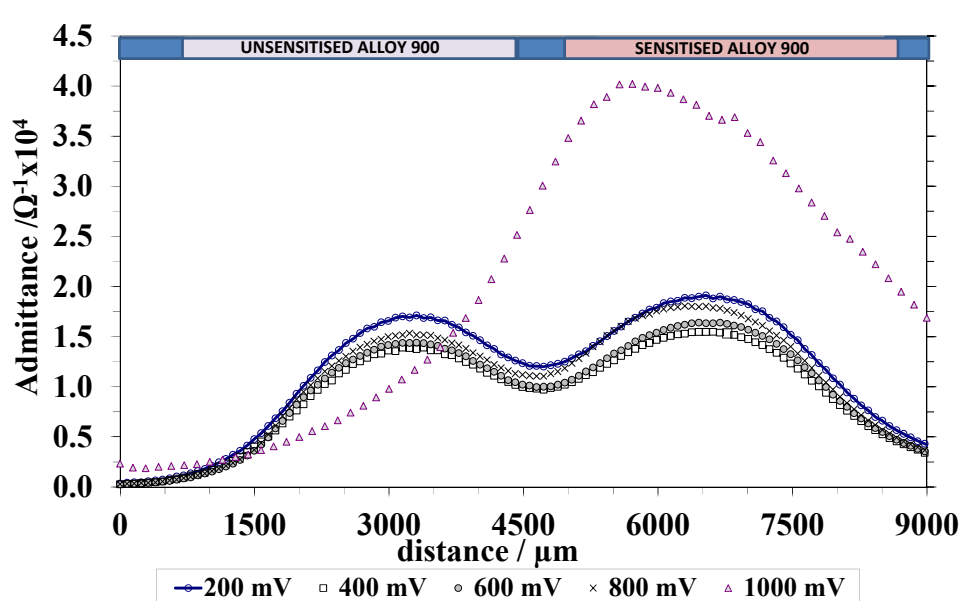

b) Admittance profiles at different imposed potentials

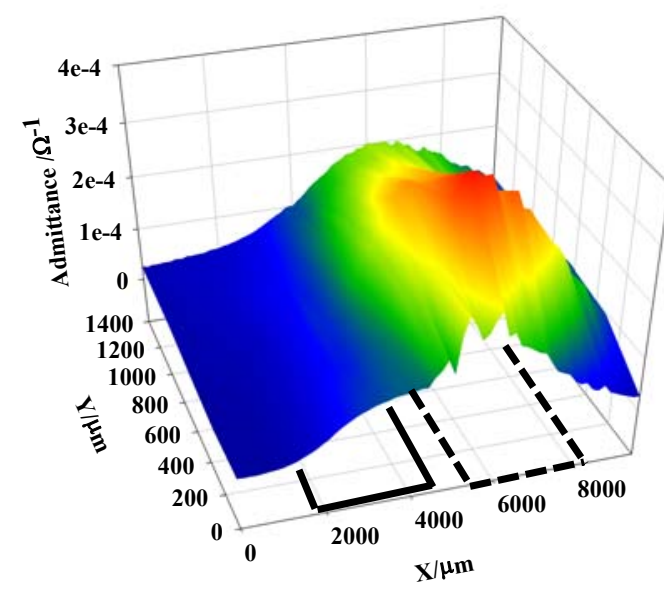

d) Admittance map of the sample when is polarised at 1 $\mathrm{V}$ vs Ag/AgCl 


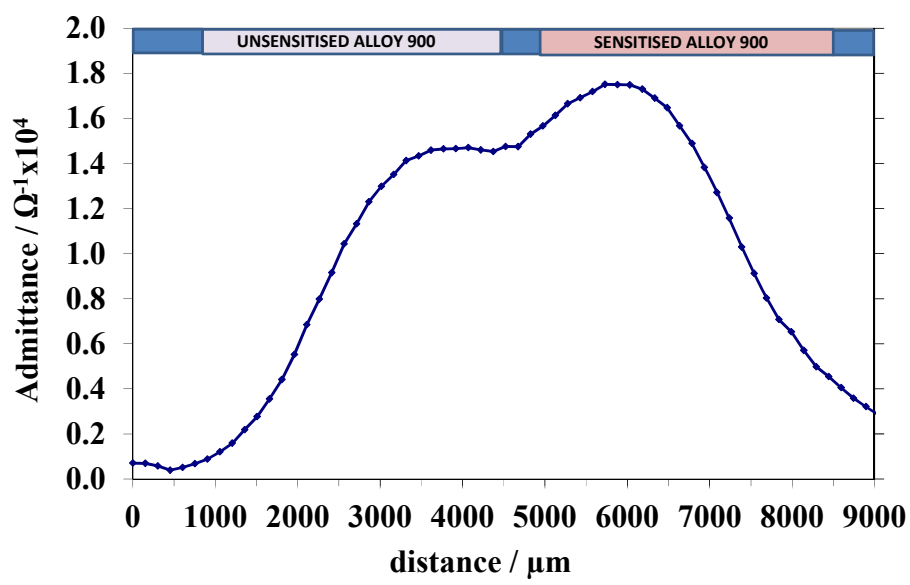

a) Admittance profiles at Open Circuit Potential

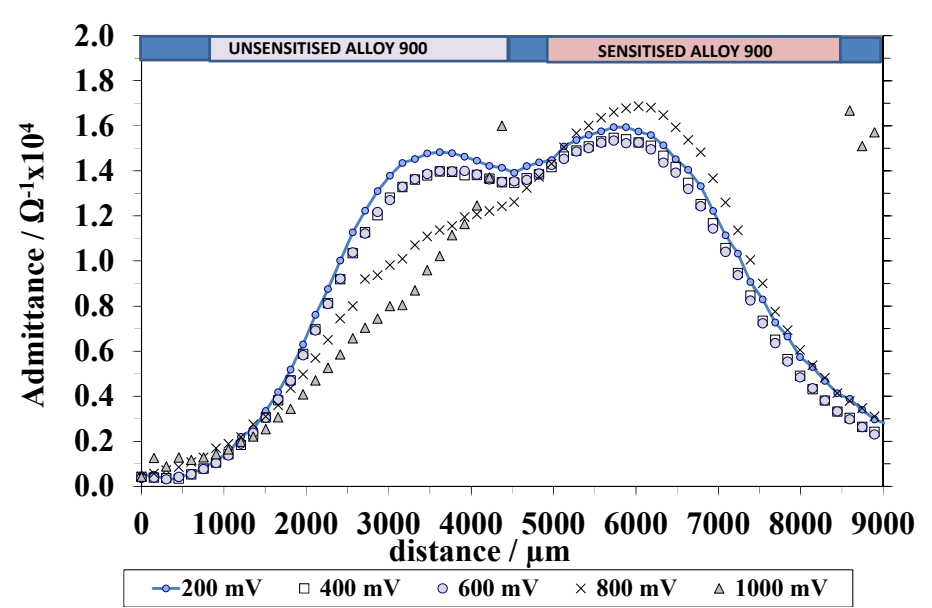

c) Admittance profiles at different imposed potentials. (Magnification)

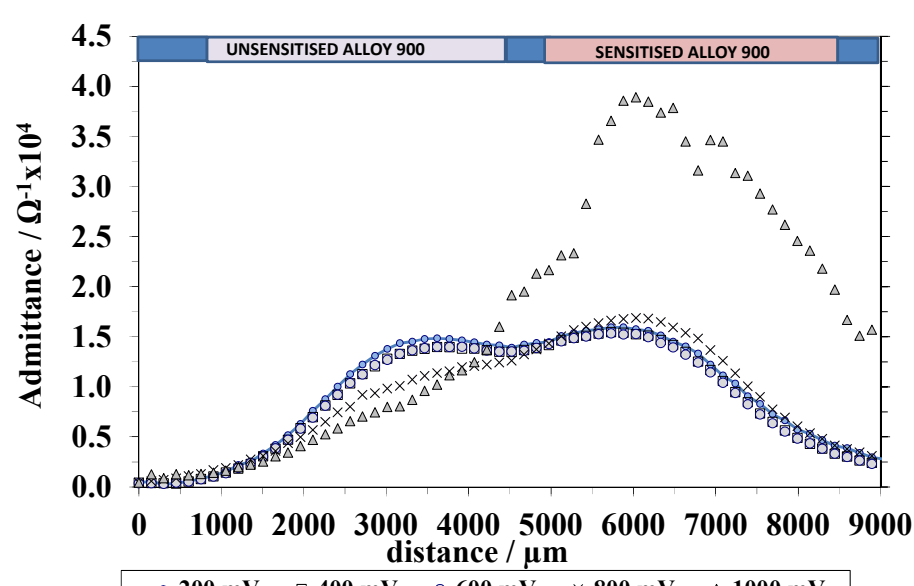

b) Admittance profiles at different imposed potentials

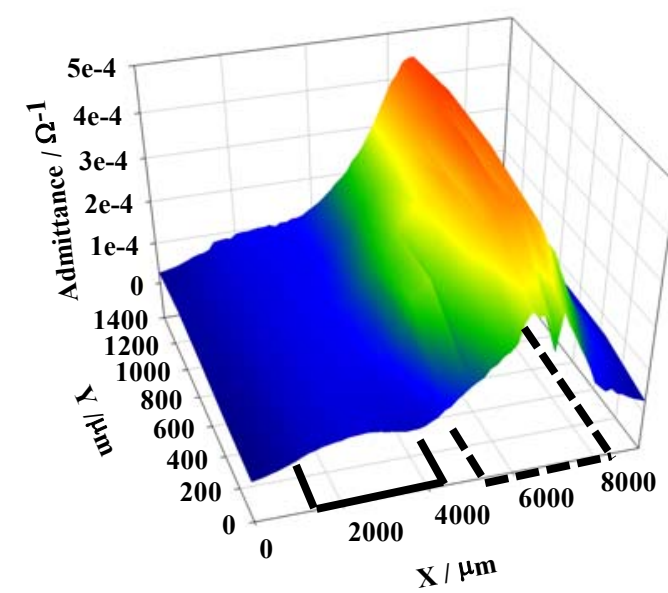

d) Admittance map of the sample when is polarised at 1 $\mathrm{V}$ vs Ag/AgCl 


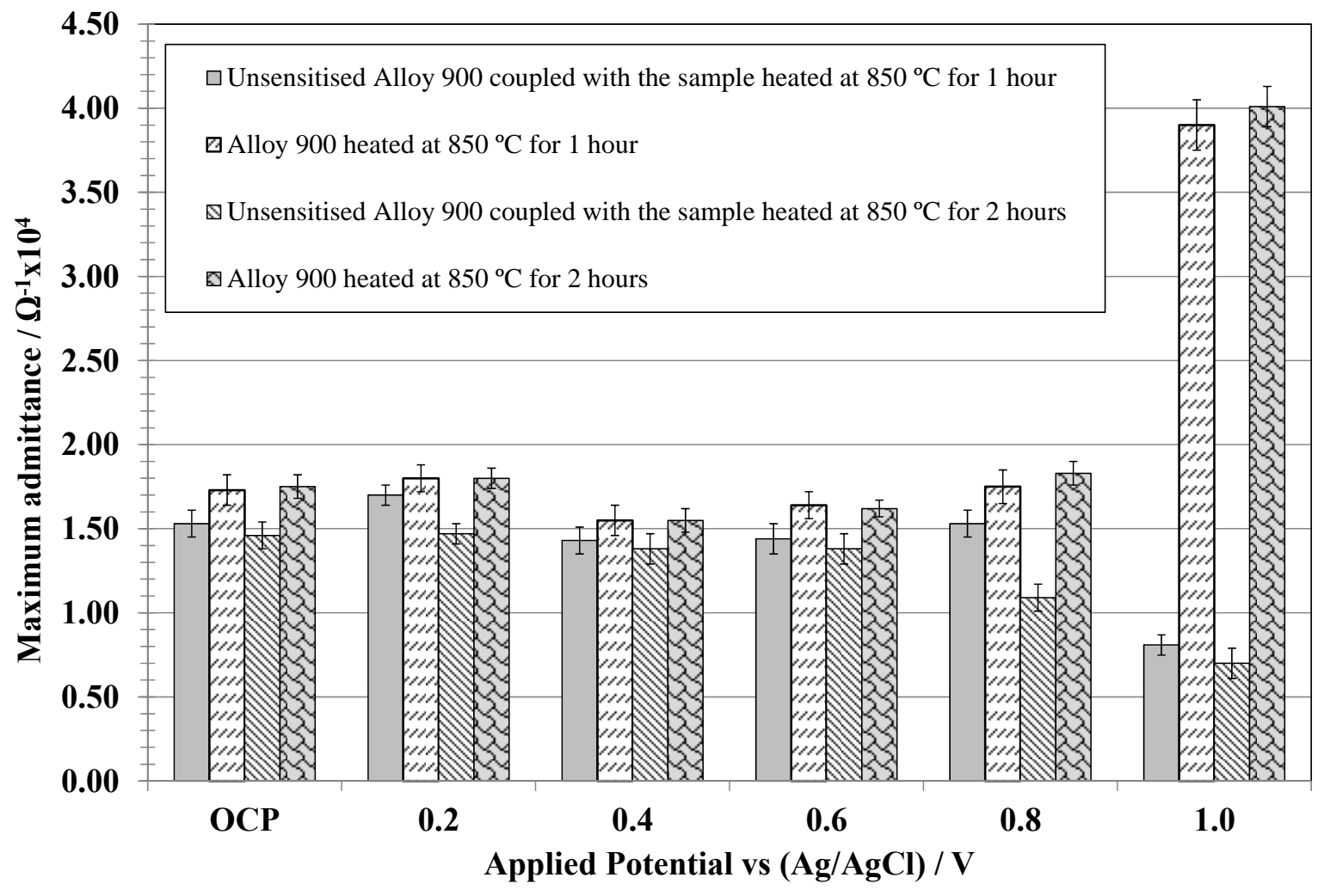

